\title{
Assessment of LNAPL in Subsurface under Fluctuating Groundwater Table using 2D Sand Tank Experiments
}

Email ID: pgupta@hy.iitr.ac.in

\author{
${ }^{2}$ Post-Doctoral Fellow, Rural Water Supply, Cranfield University, UK \\ Email ID: Basant.Yadav@cranfield.ac.uk
}

\author{
${ }^{3}$ Associate Professor, Indian Institute of Technology Roorkee \\ Postal Address: Department of Hydrology, IIT Roorkee-247667, Uttarakhand (India). \\ Email ID: brijkfhy@iitr.ac.in/brijeshy@gmail.com
}

\begin{abstract}
The focus of this study was to investigate fate and transport of toluene, a light non-aqueous phase liquids (LNAPL), in subsurface under dynamic groundwater table conditions. A series of experiments were conducted using two-dimensional (2-D) sand tank setup having the dimension of $125 \mathrm{~cm} \mathrm{~L} \times 90 \mathrm{~cm} \mathrm{H} \times 10 \mathrm{~cm} \mathrm{~W}$ and integrated with an auxiliary column of inner diameter $14 \mathrm{~cm}$ and height $120 \mathrm{~cm}$. In the beginning a steady state flow and LNAPL transport experiment was conducted under stable groundwater table condition. Thereafter, three groundwater table fluctuation experiments were conducted by rising and falling groundwater table in 2, 4 and 8 hours to maintain a rapid, general, and slow fluctuation conditions respectively. Pure phase of toluene was injected at the rate of $1 \mathrm{~mL} / \mathrm{minute}$ for a total duration of 5 minutes. The soil-water and soil vapor samples were periodically collected and analyzed for toluene concentrations. Later, the representation of 2-D sand tank setup was numerically simulated to get the response of flow and the LNAPL transport under varying groundwater table conditions. The analysis of the results show that a large LNAPL pool area $\left(250 \mathrm{~cm}^{2}\right)$ gets developed under rapid fluctuating groundwater condition which significantly enhances the dissolution rate and contributes for a high concentration of
\end{abstract}


dissolved LNAPL to the receiving receptors. The mass transfer coefficient value of $9.50 \mathrm{E}-02$; $5.80 \mathrm{E}-03 ; 3.50 \mathrm{E}-03 ; 1.20 \mathrm{E}-04 \mathrm{~m} / \mathrm{s}$ was estimated for rapid, general, slow and stable groundwater table conditions, respectively. Furthermore, the estimated Sherwood numbers ( $S h)$ were found $0.95,16.20,16.95$ and 19.30 while Peclet numbers $\left(P_{e}\right)$ were 1.80, 75.47, 80.14, and 95.06 for rapid, general, slow and stable cases respectively. This shows that the dissolution is highly affected by groundwater table which may cause loss of pollutant mass as a dissolved phase. However, the transport of dissolved LNAPL plume is comparatively fast in case of rapid fluctuating groundwater, resulting in closely space concentration isolines of toluene containing plume. A high biodegradation rate is observed in plume regions having concentration ranges from 140-160 ppm, while it decreases in the plume regions having high concentrations $(>160 \mathrm{ppm})$ and low concentrations $(<140 \mathrm{ppm})$ in these cases. In sand tank, the microbial growth was found to be increasing as plume moves away from the LNAPL pool towards low-gradient, which fortifies detrimental impact of toluene on survival of indigenous microorganisms near the LNAPL pool. The results of this study may help in implementing effective remediation technique to decontaminate LNAPL polluted sites under fluctuating groundwater table conditions, especially in (semi)-arid coastal aquifers.

Keywords: LNAPL, Groundwater fluctuation, Dissolution, Biodegradation, 2D tank experiments, Numerical modeling

\section{Introduction}

The subsurface contamination by LNAPL is widespread and challenging environmental problem, especially in coastal regions having dynamic groundwater table condition due to tidal effects. Most of the petroleum industries and refineries are located in coastal regions. The leakage of LNAPL from subsurface storage tanks and disposal sites of effluents (Nema and Gupta, 1999; Kumar et al. 2016) on surface are major source of hydrocarbons pollution of the receiving environment, especially under varying subsurface conditions. When LNAPL is released into (sub)-surface, it starts moving downward through the partially saturated zone, in response to gravitational force, until it reaches to the capillary fringe (Das and Mirzaei, 2012; Power et al. 1992a, b; 1994a, b; Illangasekare et al. 1995). A fraction of LNAPL mass is being retained in partially saturated zone and LNAPL-air mass partition (i.e. volatilization process) contributes as vapor phase contamination (Nambi and Powers, 2000; Brusseau et al. 2002, Nambi and Powers, 2003, Patterson and Davis, 2009). The remaining pool of LNAPL provides 
sufficient dissolving area to the underlying groundwater in smear zone which starts dissolving with flowing groundwater and create a dissolved phase plume (Lee and Chrysikopoulos, 1998; Kim and Chrysikopoulos, 1999; Nema and Gupta, 2003; Oostrom et al. 2006; 2007). Molecular diffusion and mechanical dispersion along with advective flux cause spreading of dissolved plume to downgradient receiving locations (Das, 2002; Yadav and Hassanizadeh, 2011; Picone et al. 2013). On the other hand, native potential microbes play significant role to degrade the dissolved LNAPL from polluted zone (Yadav et al. 2013; Basu et al. 2015, Mustapha et al. 2018).

Groundwater flow regimes play a significant role in the dissolution of pure phase LNAPL pool and its movement to the surrounding locations (Das and Nassehi, 2003; Dobson et al. 2007; Sulaymon and Gzar, 2011, Kamaruddin et al. 2011; Yadav et al. 2012). Dynamic nature of groundwater table causes significant spreading of pooled LNAPL in smear zone, which considerably increases the LNAPL-water interphase area and resulted in accelerated dissolution (Mobile et al. 2012; Vasudevan et al. 2014). Variations in groundwater table not only causes changes in the soil-water system, but also impacts the LNAPL pool behavior, if it is present on the water table and in the underlying saturated zone. The LNAPL lying on the top of the groundwater table moves down with it when the water table lowers and leave a trail of LNAPL in the unsaturated zone in the form of isolated ganglia. Subsequently when the groundwater table rises, the LNAPL pool also moves upward leaving behind a trapped amount of LNAPL in the form of disconnected blobs in the saturated zone (Lenhard et al. 2004; Kechavarzi et al. 2005). A part of the residual LNAPL in unsaturated zone gets mobilized again when the groundwater table rises. Thus, a dynamic groundwater table accelerates the dissolution of pure phase LNAPL resulting in high concentration of LNAPL plume (Legout et al. 2009). The dissolved LNAPL plume then moves along with groundwater and forms a polluted zone which features with varying concentration levels (Neale et al. 2000; Rolle et al. 2009; Zhang et al. 2014; Zhou et al. 2015; Sarikurt et al. 2017).

There is a paucity of knowledge on the impact of dynamic groundwater table conditions on LNAPL behaviors in subsurface. Groundwater fluctuation is significantly affected by heavy pumping rates to irrigate agricultural land and concurrent recharge due to return flow. Typically for shallow aquifers, a high pumping rates and return flow/recharge may cause rapid fluctuation of groundwater table. While, a slow pumping and less return flow/recharge may lead to general/slow groundwater table fluctuation. Different nature of rainfall events is also responsible for such a rapid and slow fluctuation of groundwater table. Fluctuations in the groundwater table due to various reasons including tidal effects have a profound influence on 
the spatial distribution, dissolution and biodegradation of LNAPL in the subsurface environment. This phenomenon is predominantly observed in shallow aquifer regions where most of the petrochemical industries and refineries are located and potentially at high risk of LNAPL release from the subsurface storage tanks. Thus, an extensive study was conducted to investigate LNAPL fate and transport under fluctuating groundwater table conditions using a series of 2-D sand tank experiments. A better understanding of fate and transport of LNAPL under varying subsurface water table condition is required which in turn can help in designing effectively remediation technologies and to accurately predict their clean-up times and the associated cost.

\section{Materials and Methods}

In this study, the behavior of pooled pure phase LNAPL and its dissolved plume in subsurface under stable and fluctuating groundwater table conditions is investigated using a series of twodimensional laboratory experiments and numerical modelling. The preliminary experiments were conducted to characterize the flow and transport parameters of the developed subsurface soil-water system. Mechanical sieve analysis was performed to find the particle size distribution of the sand which is listed in Table 1 along with other physical parameters. The porosity of sand packing was determined using oven dry and volumetric methods. Further, the hydraulic conductivity of the system was estimated using a constant head permeameter. To see the behavior of the pooled LNAPL and dissolved phase plume, a series of two dimensional sand tank experiments were performed by considering varying groundwater table conditions. A two dimensional sand tank setup filled with homogenous sand was used to conduct the laboratory experiment under (1) steady-state groundwater condition and (2) three different dynamic groundwater table fluctuation conditions, separately. Lastly, the soil-water system was numerically simulated using HYDRUS 2D model considering the laboratory investigated soil-water and solute transport parameters.

8

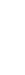

(

.


Table 1. Properties of the sand used in the laboratory experiments.

Characteristic Values

\begin{tabular}{cc}
\hline Type & Medium Sand \\
Grain Size & $0.5-1 \mathrm{~mm}$ \\
Particle Size $>1 \mathrm{~mm}$ & $1.71 \pm 0.5 \%$ \\
Particle Size $0.5 \mathrm{~mm}-1 \mathrm{~mm}$ & $98.27 \pm 0.5 \%$ \\
Particle Size $<0.5 \mathrm{~mm}$ & $0.02 \pm 0.01 \%$ \\
Effective Porosity & $0.33 \pm 0.02 \%$ \\
Bulk Density & $1.52 \pm 0.1 \mathrm{~g} / \mathrm{cm}^{3}$ \\
Grain Density & $2.31 \pm 0.1 \mathrm{~g} / \mathrm{cm}^{3}$ \\
\hline
\end{tabular}

\subsection{Two Dimensional Sand Tank Setup}

138 Two dimensional sand tank setup used in the study was specially designed using $2.5 \mathrm{~mm}$ thick 139 stainless steel formed box with inner dimensions of $150 \mathrm{~cm}$-long $\times 120 \mathrm{~cm}$-high $\times 10 \mathrm{~cm}$-deep

140 (Figure 1). Two wells were installed at each side of tank and front cover of the tank was made141 up of a thick glass sheet for enabling observations. Indian standard clean sand (650 grade-II) 142 of particle size $0.5-1 \mathrm{~mm}$ free from organic matter was packed in the central chamber between 143 both the wells up to a height of $90 \mathrm{~cm}$. The top $30 \mathrm{~cm}$ thick sand pack was kept as head-space 144 to maintain aerobic condition. The porous media was oversaturated before pouring it into the 145 column setup to create a homogenous packing. During this filling, a comb-like metallic tool 146 was used to smooth the sand surface for avoiding a layered structure of the porous media. The 147 extra water was then gravitationally drained out from the bottom of tank setup. The system was 148 then flushed at maximum velocity until the effluent water was free of suspended fine material. 149 After each of the experiments, the used sand was replaced with fresh sand pack the new set of 150 the experiments following the packing procedure as describes earlier. The wells were used as 151 upstream (high pressure) and downstream (low pressure) reservoir to maintain the water table. 152 An auxiliary column containing the collected groundwater was connected to the inlet port of 153 upstream well with viton tubes of a peristaltic pump. This peristaltic pump refers as "upstream 154 pump" was used to supply the groundwater to the sand tank through the upstream well. The objective of this auxiliary column was to provide sufficient groundwater storage required to maintain the dynamic groundwater table conditions (Figure 1a). Similarly, the outlet of the 
downstream well was connected to another peristaltic pump (refer herein as downstream pump) to extract the groundwater and recirculate to the auxiliary column. The flow rate of the pumps was adjustable so that the desired pressure difference in the two reservoirs can be maintained and thereby controlling the groundwater flow within the tank setup. A LNAPL release port was installed just below the top surface of sand packing about $20 \mathrm{~cm}$ from the upstream well. The sampling ports having equal horizontal spacing of $15.5 \mathrm{~cm}$ are situated at 30 and $60 \mathrm{~cm}$ height from the bottom of the tank setup in two horizontal layers (figure 1b). Piezometers were attached to the tank to measure the positions of the groundwater table during experiments. Filtration screens were fixed around the inlet and outlet valves to prevent the entrance of the sand particles in the connecting viton tubes.

A series of tracer transport experiments were performed to determine the longitudinal and vertical dispersivity of sand under fast, base and slow groundwater velocities. A solution of tap water and sodium chloride with an initial concentration of $1000 \mathrm{mg} / \mathrm{l}$ was continuously injected to the tank for the selected groundwater fluctuation cases. The water samples were routinely collected from the sampling port located at $50 \mathrm{~cm}$ away (at $X: 45 ; Y: 50 \mathrm{~cm}$ ) in the lower-gradient side from the injection port of the top sampling layer and the tracer concentrations were measured using portable conductivity meter. The longitudinal dispersivity $\left(D_{L}\right)$ resulted from the dispersivity flux were estimated using the breakthrough curves (BTCs) obtained from the tracer experiments. Time values corresponding to relative concentration ratios of $84 \%, 50 \%$, and $16 \%$ were used in calculating the dispersion coefficient $\left(D_{L}\right)$ and longitudinal dispersivity $\left(\alpha_{L}\right)$ as proposed by Sulaymon and Gzar (2011). In the equation, $D_{i j}=\tau D_{*}+D_{x}$, the first term resulted from diffusive flux was estimated by multiplying the diffusion coefficient of toluene i.e. $6.3 \times 10^{-6}\left[\mathrm{~cm}^{2} / \mathrm{sec}\right]$ and tortuosity of sand i.e. 1.43 (Sulaymon and Gzar, 2011). The vertical dispersivity $\left(D_{V}\right)$ were considered 0.1 times of the obtained longitudinal dispersivity (Dobson et al. 2007).

A series of LNAPL transport experiments were performed using 2D sand tank setup for stable/steady and three different groundwater table level conditions. Under steady-state condition, a constant groundwater flux was applied as inflow (using the upstream pump) and the same was extracted as outflow (using the down-stream pump) to maintain a constant flow velocity in the horizontal direction and, hence, keeping the water table location at a constant height. However, in rapid, general and slow groundwater level fluctuation experiments the inflow/outflow flux were controlled by peristaltic pump to maintain a raising of the water 
table by $5 \mathrm{~cm}$ in 1,2 , and 4 hours respectively. The groundwater table was then lowered in the same manner; a drop of $5 \mathrm{~cm}$ was achieved in subsequent 1,2 and 4 hours for rapid, general and slow fluctuation conditions, respectively. It may be noted herein that "one fluctuation cycle" refers to a complete high-low-high cycle of groundwater table levels.

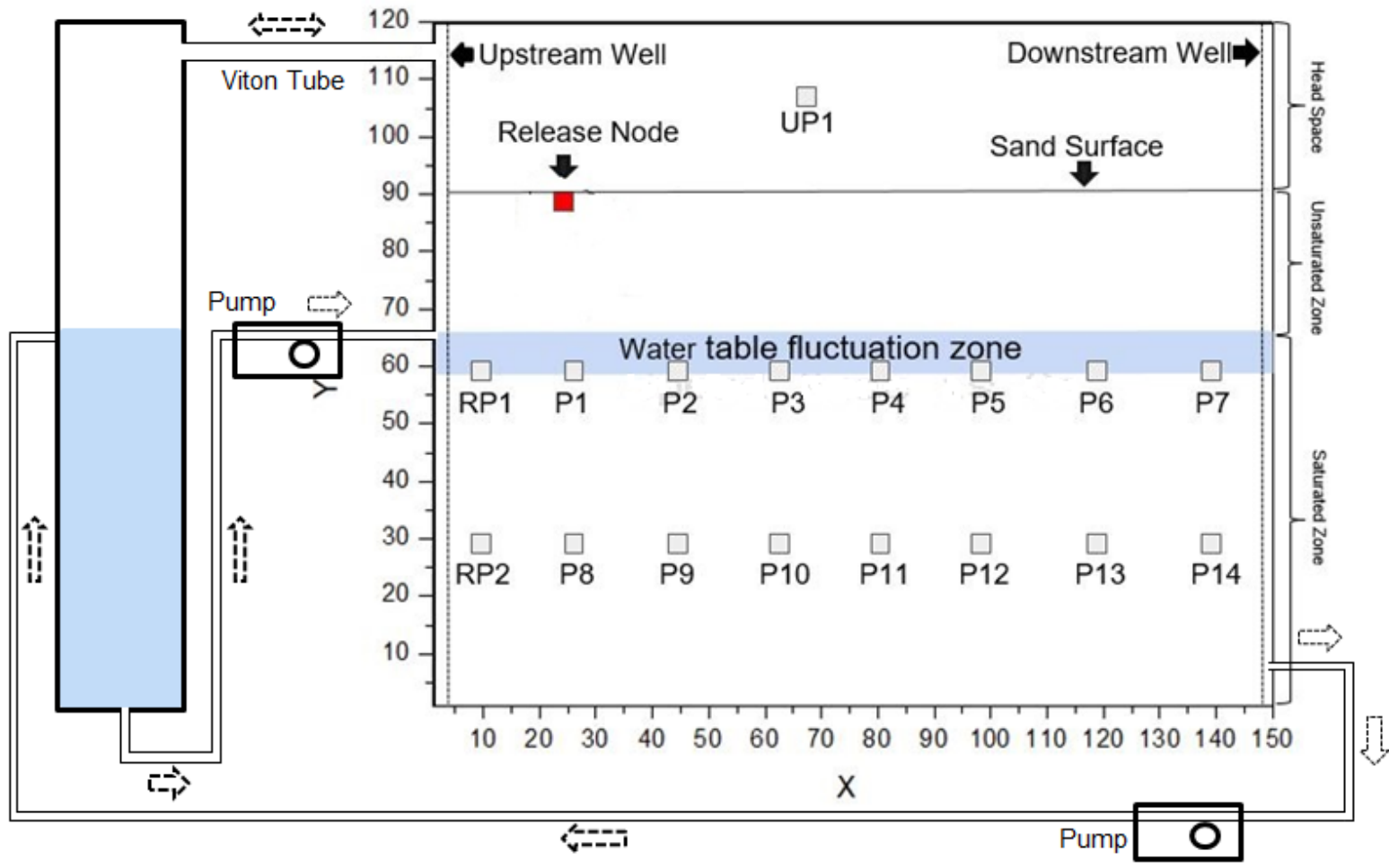

Figure 1. Schematic diagram of 2D sand tank setup integrated with an auxiliary column used to investigate fate and transport of LNAPL in subsurface under dynamic groundwater table conditions.

Rising of groundwater table was maintained by pumping the water from the auxiliary column to the upstream well and closing the outflow from the downstream well for a target duration of respective fluctuation conditions. Likewise, groundwater falling was maintained by extracting water from the downstream well and closing the inflow to the sand tank from the auxiliary column for the same duration. Such switching of the peristaltic pump was adjustable and calibrated for a target duration of respective fluctuation conditions. A brief pumping details of different considered cases are listed in Table 2. To maintain a rise and fall of $5 \mathrm{~cm},(150 \mathrm{~cm}$-long $\times 05 \mathrm{~cm}$-magnitude of fluctuation $\times 10 \mathrm{~cm}$-deep $\times 33 \%$ porosity) $0.002475 \mathrm{~m}^{3}$ or 2.475 liters of groundwater was required as inflow and outflow. Pure phase toluene was released from the top surface of the tank set up 
210 to create a pool of the LNAPL above the groundwater table which was varied in the range of $21155-60 \mathrm{~cm}$ level from the tank bottom. The toluene (Merck with $99.9 \%$ purity) was injected 212 at a constant rate of $02 \mathrm{ml} / \mathrm{min}$ for a duration of 5 minutes using an air-tight syringe. 213 Periodically, a small amount of soil water samples from both the layers and the soil vapor 214 samples from head-space were collected carefully for the analysis.

Table 2. Inflow and outflow pumping strategies of groundwater table fluctuation cases.

\begin{tabular}{|c|c|c|c|c|c|c|}
\hline \multirow{3}{*}{ Conditions } & \multirow{2}{*}{\multicolumn{2}{|c|}{$\begin{array}{l}\text { Inflow } \\
\text { Pumping }\end{array}$}} & \multicolumn{2}{|c|}{ Outflow } & \multirow[b]{2}{*}{ Total } & \multirow[t]{2}{*}{ Pumping Rate } \\
\hline & & & & ping & & \\
\hline & Rise & Fall & Rise & Fall & Duration & \\
\hline Rapid fluctuation & 1 hour & X & $x$ & 1 hour & 2 hours & $2475.0 \mathrm{~mL} / \mathrm{hr}$ \\
\hline General fluctuation & 2 hours & X & $x$ & 2 hours & 4 hours & $1237.5 \mathrm{~mL} / \mathrm{hr}$ \\
\hline Slow fluctuation & 4 hours & X & $x$ & 4 hours & 8 hours & $618.7 \mathrm{~mL} / \mathrm{hr}$ \\
\hline
\end{tabular}

217

218

219

220

221

222

223

224

225

226

227

228

229

230

231

232

233

234

\subsection{Sample Analysis}

Soil water samples were collected periodically using needles attached with syringes (Hamilton gold) from the sampling ports embedded in the sampling layers in saturated zone (Figure 1). The samples were transferred into vials (Agilent vials: Agilent Product No. 5190/1599) having air tight red septa caps without any air contacts. Similarly, soil vapor samples were collected from sampling ports installed in the headspace. The collected samples were analyzed using Gas chromatography-mass spectrometry (GC-MS) (Agilent 7890B $)$ in triplicates. A chrompack capillary column $(30 \mathrm{~m} \times 0.25 \mathrm{~mm}$, Silicone coating of $0.25 \mu \mathrm{m}$ ) was used for toluene analysis. Helium was employed as the carrier gas at a flow rate of $25 \mathrm{~mL} / \mathrm{min}$. Similarly, air and nitrogen were used with a flow rate of $20 \mathrm{~mL} / \mathrm{min}$ during GCMS analysis. During the measurements, temperature of injection port, oven, and detector port was kept at $150^{\circ} \mathrm{C}, 120^{\circ} \mathrm{C}$, and $150^{\circ} \mathrm{C}$, respectively. One set of collected samples were also analyzed using gas chromatography/combustion/isotope ratio mass spectrometry (GC/C/IRMS) technique to capture pure phase LNAPL (Dempster et al. 1997). 


\subsection{Microbiological Analysis}

The microbial population in the soil water zone was counted using heterotrophic or standard plate count methods (No. 9215C). In this method, colony forming units (CFU) for live heterotrophic bacteria was estimated from the collected soil-water samples during laboratory experiments. The soil water samples for microbial population count were collected from M1 and M7 ports of top layer and M8 and M14 ports of bottom layer (Fig 2). After the sample collection, all the collected samples were diluted with a factor of $10^{1}$ to $10^{-5}$ and mechanically shaken for 15 seconds. Growth media was prepared using a combination of $20 \mathrm{~g}$ protease peptone; $1.5 \mathrm{~g}$ of $\mathrm{K}_{2} \mathrm{HPO}_{4} ; 1.5 \mathrm{~g}$ of $\mathrm{MgSO}_{4} .7 \mathrm{H}_{2} \mathrm{O}$; and $20 \mathrm{~g}$ of Agar. Final $\mathrm{pH}$ of media was adjusted to 7.2 by adding $1 \mathrm{~N} \mathrm{NaOH}$, before autoclaving at $121^{\circ} \mathrm{C}$ for 15 minutes. The laminar air flow setup was wiped with the $70 \%$ ethanol and UV light for the 15 minutes to avoid any background microbial contaminations. Well marked (sample number, dilution, and date) plates were poured with $30 \mathrm{~mL}$ prepared growth media and kept still for few minutes to solidify agar surface. Thereafter, diluted samples were inoculated with the help of spreader on agar surface of respective plates. Successively, all the plates were incubated for 48 hours at $36 \pm 1^{\circ} \mathrm{C}$ for. After the incubation, colony was counted manually using the quadrate method. Plates having an un-countable number (or too numerous) was considered as overgrowth. In this study, microbial populations were counted with the 12 hours' interval to see the impact of LNAPL transport on microbial growth under fluctuating groundwater table conditions. Thus, above mentioned microbial counting procedures were performed for each experiments separately. A comparative account of such bacterial count during groundwater table fluctuation experiments gives a clear idea on how groundwater fluctuating conditions affects the LNAPL fate and transport in the subsurface.

\section{Numerical Modeling}

To solve the dissolved phase LNAPL transport in saturated zone 2D form of mass balance equation used as:

$$
\frac{\partial}{\partial t}\left(n S_{f} C_{i f}\right)=-\nabla \cdot\left(q_{f} C_{i f}\right)+\nabla \cdot\left(n S_{f} D_{i f} . \nabla C_{i f}\right)+K_{i f}-S
$$

Where $C_{i f}$ is NAPL compound in $f$ phase $\left[\mathrm{ML}^{-3}\right], q_{f}$ is discharge through soil profile [LT $\left.{ }^{-1}\right]$, $n$ is porosity of soil $\left[\mathrm{L}^{3} \mathrm{~L}^{-3}\right], t$ is time [T], $K_{\text {if }}$ is the dissolution rate of LNAPL $\left[\mathrm{ML}^{-3} \mathrm{~T}^{-1}\right]$ was observed using characteristic length of LNAPL pool and equilibrium concentration in dissolved 
phase. Likewise, $S$ is biodegradation rate $\left[\mathrm{ML}^{-3} \mathrm{~T}^{-1}\right]$ (as sink term) was obtained using (control and live) microcosms experiments. $D_{i f}$ is hydrodynamic dispersion $\left[\mathrm{L}^{2} \mathrm{~T}^{-1}\right]$ which was obtained

269

270

271

272

273

274

275

276

277

278

279

280

281

282

283

284

285

286

287

288

289

290

291

292

293

294

295

296

297

298

299 using breakthrough curves (BTCs) of tracer transport experiment. The HYDRUS 2D model was used to solve governing equation for water flow and solute transport (Simunek et al. 1996). A two dimensional numerical domain having similar dimension of sand tank was created to simulate soil water flow and LNAPL transport through saturated zones. Thus, in this case $S_{f}$ i.e. fluid saturation in pore space $\left[\mathrm{L}^{3} \mathrm{~L}^{-3}\right]$ was taken as 1 as the media fully saturated. The simulation domain was discretised in small grids of size $1 \mathrm{~mm}$ in a hexahedral geometry for solving the governing equation numerically. The Galerkin finite elements method integrated with Crank-Nicholson iterative scheme was used for the solution. The soil water flow and solute transport parameters listed in table 1 were used as model input parameters. The hydraulic behavior or parameters were obtained by inverse solution in HYDRUS 2D (Simunek et al., 2012).

\subsection{Initial and boundary conditions}

The simulation domain was assigned no background concentration (zero) as initial solute condition. The saturated moisture content was taken as the initial moisture level of the domain and the top boundary was considered as the water table. Right side boundary (was taken as continuous flux by incorporating respective pulse of influx for 1, 2, and 4 hours to maintain groundwater table fluctuation along with base groundwater velocity. Similarly, left side boundary was taken as a pulse out-flux for the respective cases. In case of stable groundwater table condition, constant influx and out-flux was taken without pulse condition. No flux condition was considered as the lower boundary condition. A LNAPL releasing point was incorporated at same location as of two dimensional laboratory sand tank setup.

\section{Results and Discussion}

The breakthrough curves (BTCs) of tracer experiments under stable and different groundwater fluctuation cases are presented in Figure 2 for rapid, general and slow groundwater table fluctuation conditions represented as GWTF-C1, GWTF-C2, GWTF-C3, respectively. The slope of the BTCs shown in Figure 2 are of similar trend, suggesting that the sand was packed uniformly in each set of experiments without any significant preferential flow paths. The best fit values of dispersion coefficient values are 0.000246, 0.0000171, 0.0000108, 0.0000073 
$\mathrm{m}^{2} / \mathrm{s}$ for rapid, general, slow, and stable groundwater table fluctuation conditions respectively.

301 Similarly, estimated longitudinal dispersivity values are $1.23,0.72,0.28,0.12 \mathrm{~m}$ for rapid, 302 general, slow, and stable groundwater table fluctuation conditions respectively. The observed 303 values of dispersivity was used to simulate dissolved LNAPL plume in identified domain under 304 corresponding groundwater table case.

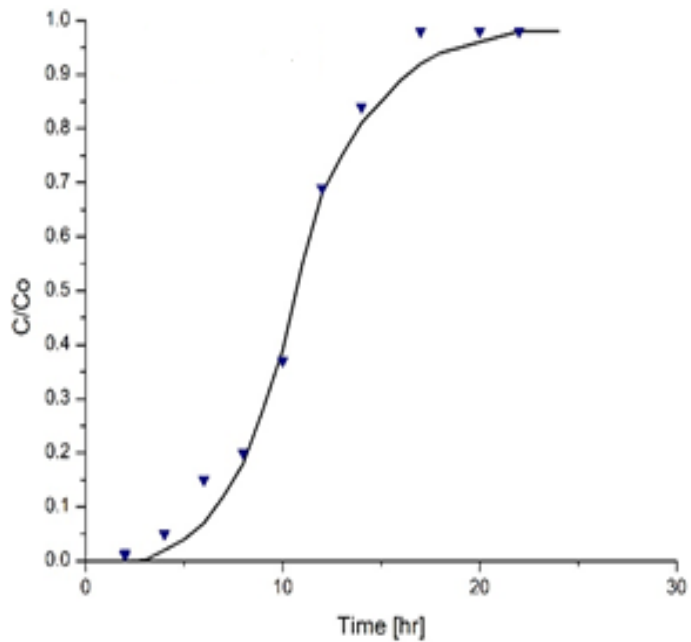

(a) GWTF-C1

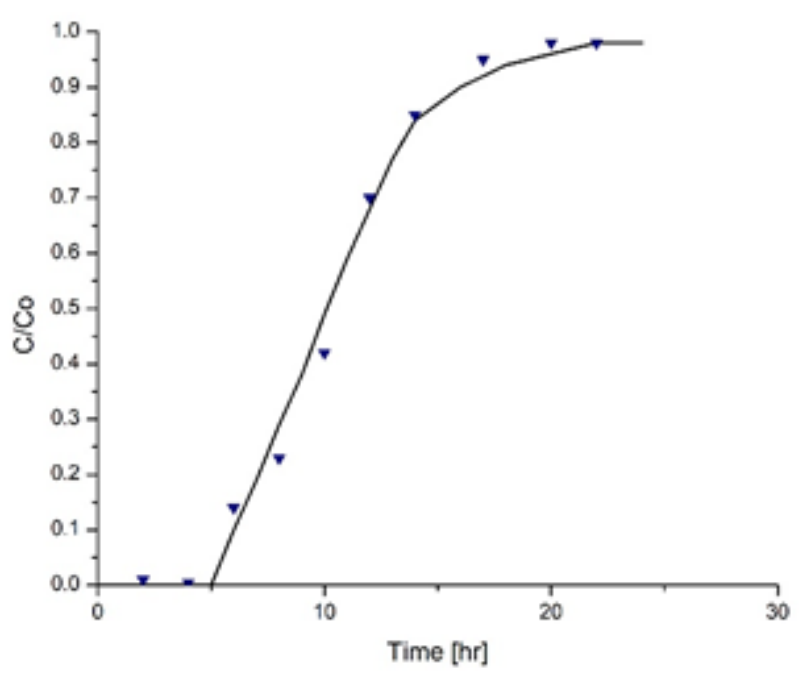

(c) GWTF-C3

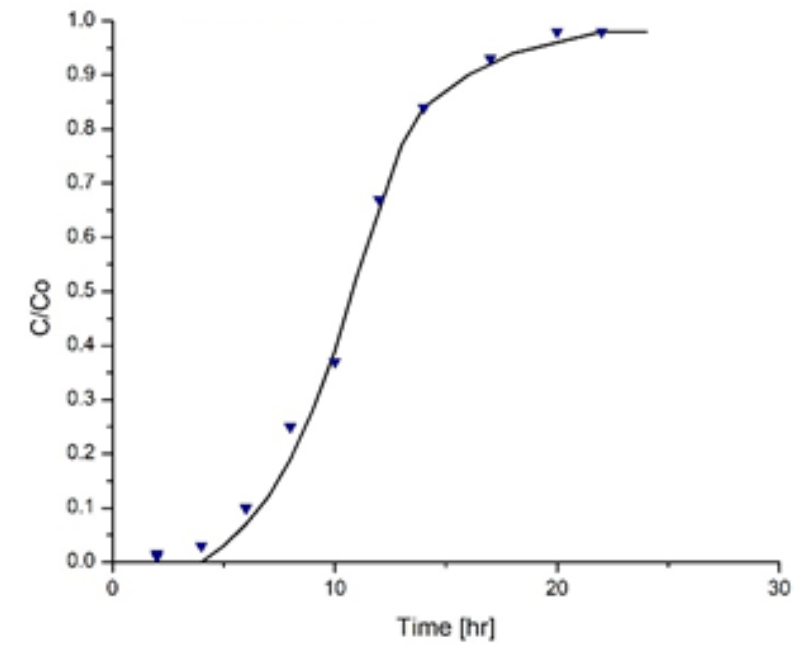

(b) GWTF-C2

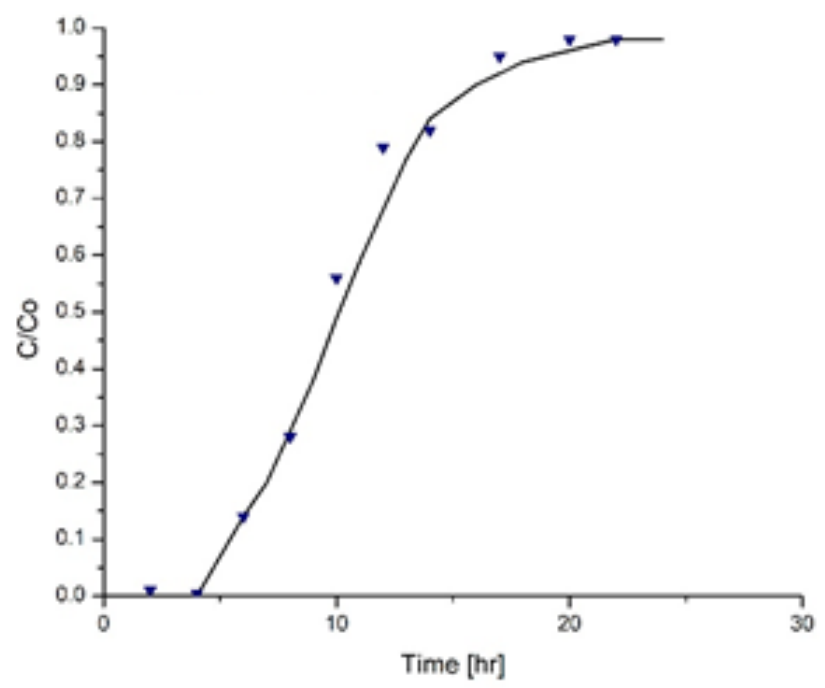

(d) GWTF-C4 (d) stable groundwater fluctuation conditions. 


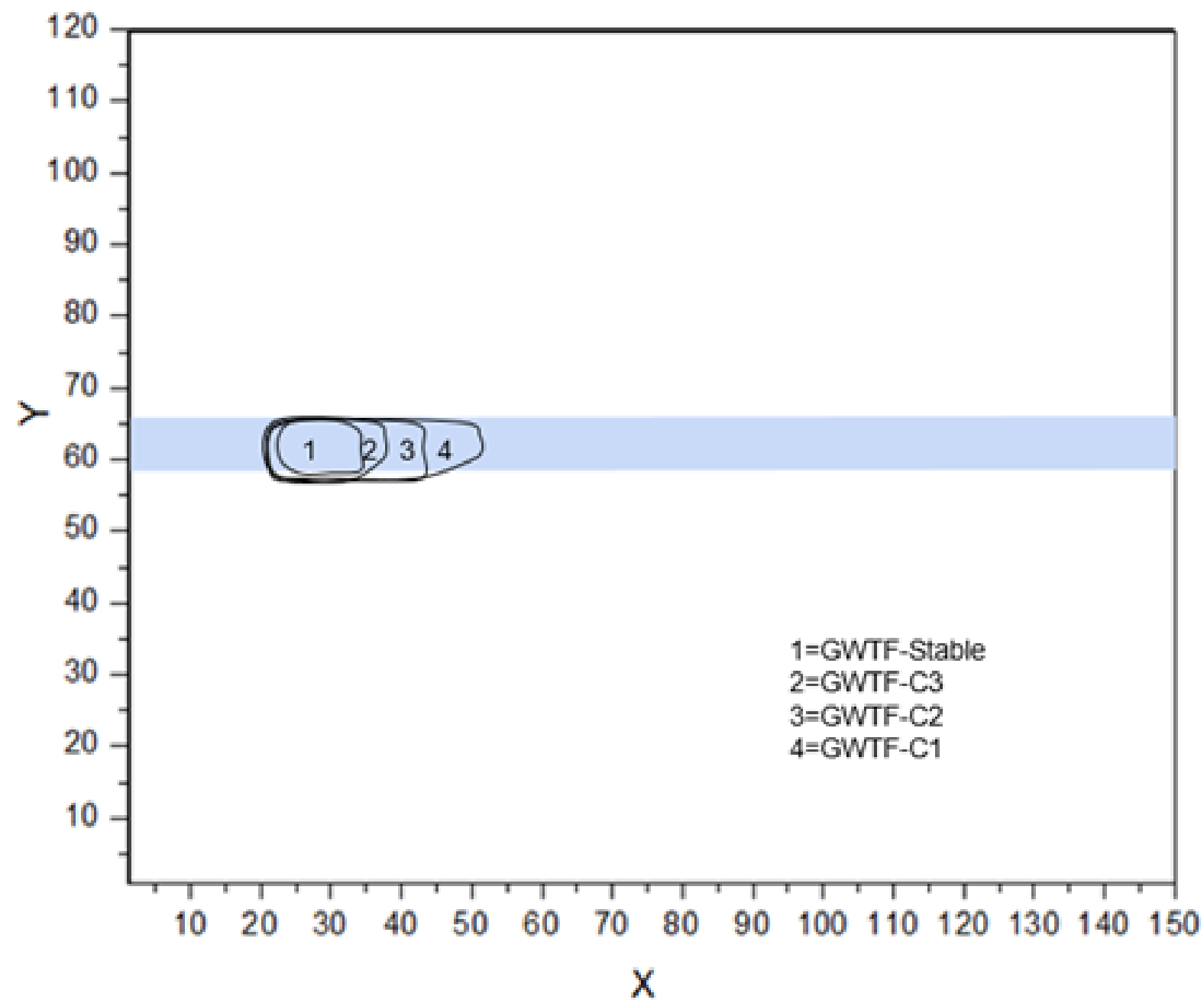

Figure 3: Coverage of the LNAPL pool in smear zone subjected to different groundwater

\subsection{Pure phase LNAPL coverage and dissolution}

317 An effort has been made to capture LNAPL pool area in two dimensional sand tank 318 experiments under stable and fluctuating groundwater cases. For this purpose, periodically soil319 water samples were analyzed by GC-MS/IRMS technique (Dempster et al. 1997). The interpreted boundary of pure phase LNAPL pool is presented in Figure 3 which shows a total area of 250, 200, 160 and $70 \mathrm{~cm}^{2}$ covered under rapid, general, slow and stable groundwater fluctuation cases, respectively.

Experimentally observed area of pure phase LNAPL pool was used to determine the characteristic length of the pool and for the estimation of dissolution rate. It can be observed from the results that the rapid groundwater fluctuation causes the pure phase LNAPL pool to spread over more area then the stable groundwater case. A high groundwater velocity 
due to rapid fluctuation in groundwater governs the excess spreading of LNAPL in flow directions. Spreading of pure phase LNAPL over a large area provides more dissolving surface as LNAPL-water interphase to underlying flowing groundwater resulting into more dissolution rates. Similarly, the large LNAPL pool contributes more LNAPL vapour to the overlying unsaturated zone. Further, the volume of water contacting the LNAPL pool surface increases as it spread in large area which also leads to high dissolution rates. This in turn significantly increases dissolved phase concentration load to receiving groundwater and vapor contamination to unsaturated pore air (Dobson et al. 2007; Vasudevan et al. 2014). On the other hand, large coverage of pool contributes more LNAPL mass to capillary ganglia as smaller blobs/fingering, which also play significant role in dissolution under rapid groundwater table conditions. As noted by Sarikurt et al. (2017), the contact time and area of LNAPL-water interphase is significant for dissolution rate and subsequent transport of dissolved LNAPL in subsurface. Similarly, Sulaymon and Gzar (2011) highlighted that length of LNAPL-water interphase plays important role to control the equilibrium concentration of dissolved LNAPL plume. Results of this study confirm that the groundwater table fluctuation causes more spreading of pure phase LNAPL pool itself which ultimately provide more LNAPL-water dissolving area in smear zone. High dissolution rate from large LNAPL pool contributes high concentration of dissolved LNAPL to the downgradient ports. The estimated LNAPL pool coverage area under different cases can be used to forecast dissolved LNAPL plume under dynamic groundwater flow conditions.

\subsection{Vapor phase concentrations}

The vapor phase LNAPL concentrations are plotted as BTC in Figure 4. The BTC shows a high LNAPL concentration in case of rapid fluctuating groundwater table followed by general, slow and stable groundwater table case. The vapor equilibrium concentration was observed as 210230 ppm in fluctuating condition while 180-185 ppm was observed in stable groundwater case. This means a raising groundwater table carries pure phase LNAPL mass upward and a falling groundwater allows LNAPL to move downward. During dynamics of groundwater level, the trapped LNAPL remain behind in smear zone which creates a large interphase area of airLNAPL/water (Powers et al. 1992). Therefore, more vapor phase concentration was observed from the residual LNAPL. These results are in line with the findings of study conducted by Oostrom et al. (2006) with 2D experiments under water table dynamic conditions. The study found a considerable residual LNAPL saturation in smear zone. The high vapor concentration can also be attributed to the partition of LNAPL from large dissolved phase plume having high 
concentration. Further, lowering of groundwater table increases air-filled porosity in smear zone, which eventually affects vapor phase LNAPL partition. The BTC of different groundwater table fluctuation experiments confirms that the vapor intrusion is highly dependent on the nature of groundwater table conditions (Patterson and Davis, 2009). High vapor LNAPL in unsaturated pores may become toxic for the indigenous microorganisms.

368

369

370 371 372

373

374

375 376

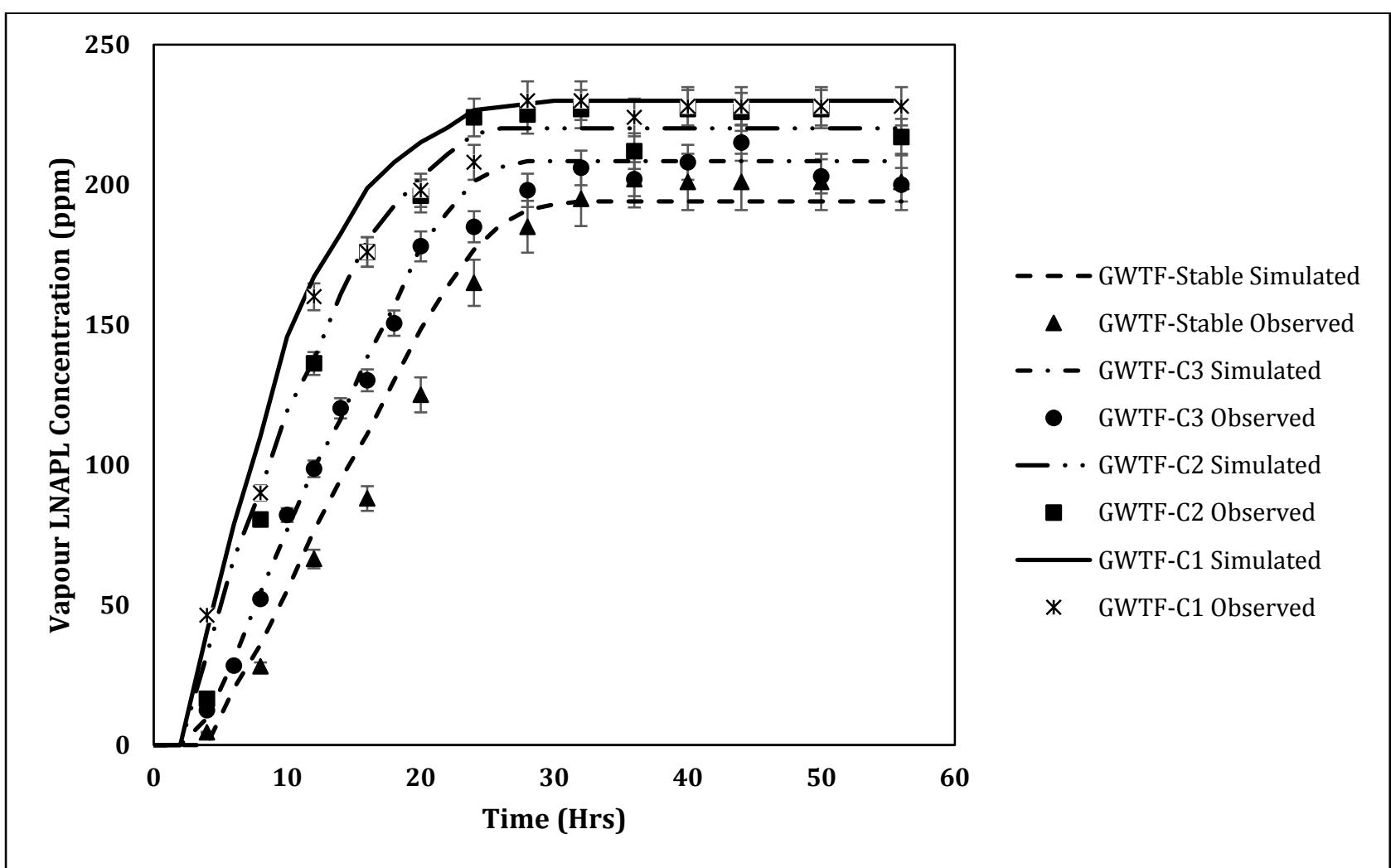

Figure 4: BTC representing LNAPL concentration in soil air in 2D sand tank under stable and fluctuation groundwater table conditions.

The measured pure phase LNAPL pool area was used to estimate its characteristic length of LNAPL pool $\left(l_{(c)}\right)$ under stable and fluctuating groundwater conditions. The observed values of $l_{(c)}$ was found $15.81,14.15,12.64$, and $8.36 \mathrm{~cm}$ under rapid, general, slow and stable groundwater fluctuation conditions, respectively. The estimated value of mass transfer coefficient $\left(k^{*}\right)$ are listed in Table 3. The estimated Sherwood numbers ( $S h$ ) were found 0.95 , 16.20, 16.95 and 19.30 while Peclet numbers $\left(P_{e}\right)$ were 1.80, 75.47, 80.14, and 95.06 for rapid, general, slow and stable cases respectively. A high value of $S h$ indicates that dissolution was a dominating process under fluctuating groundwater conditions. The reason for high $S h$ can be 
attributed to the large pool spreading, which provides more LNAPL-water interphase under fluctuating groundwater condition. Further, more contact time of underlying groundwater with the large dissolving LNAPL pool also accelerate the dissolution rate. Likewise, high $P_{e}$ indicates that the advective flow was dominant than the diffusive flow under fluctuating groundwater conditions. However, one cannot ignore the importance of diffusive flux under stable groundwater flow regimes. The correlation $S h$ with $P_{e}$ is presented in Figure 5 with the coefficient of determination $\left(\mathrm{R}^{2}\right)$ value of 0.998 . This kind of high correlation between $S h$ and $P_{e}$ was also reported in a recent study by Sarikurt et al. (2017).

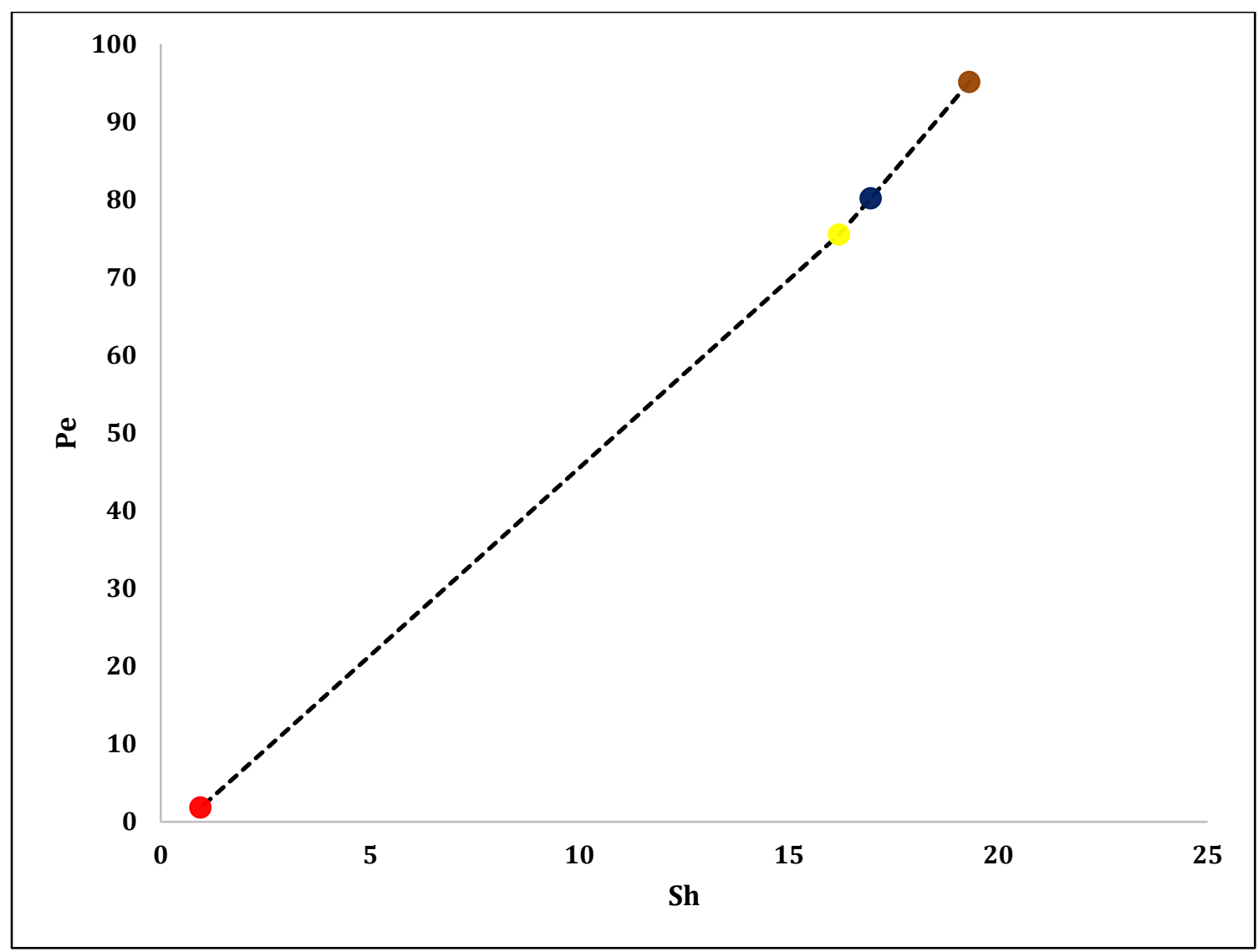

Figure 5: Correlation between $S h$ and $P_{e}$. Red, yellow, blue and green circle represent stable, slow, general and rapid groundwater fluctuation conditions respectively. 
Table 3: Estimated values of $k^{*}$ and corresponding values of $S h$ and $P_{e}$ under dynamic groundwater table conditions

\begin{tabular}{lccc}
\hline Conditions & $\begin{array}{c}\text { Mass transfer } \\
\text { coefficient } \\
k^{*}\end{array}$ & $\begin{array}{c}\text { Sherwood Number } \\
(\mathrm{m} / \mathrm{s})\end{array}$ & $\begin{array}{c}\text { Peclet Number } \\
(-)\end{array}$ \\
\hline GWTF-C1 & $9.50 \mathrm{E}-02$ & 19.30 & $P_{e}$ \\
& $5.80 \mathrm{E}-03$ & 16.95 & 95.06 \\
GWTF-C2 & $3.50 \mathrm{E}-03$ & 16.20 & 80.14 \\
GWTF-C3 & $1.20 \mathrm{E}-04$ & 0.95 & 75.47 \\
GWTF-Stable & & & 1.80 \\
\hline
\end{tabular}

400

401

402

403

404

405

406

407

408

409

410

411

412

413

414

415

416

417

418

419

420

421

422

423

\subsection{Dissolved phase concentrations}

Dissolved LNAPL concentrations as a function of time for all four cases are presented in figures 6-7. In figure $6 \mathrm{a}, \mathrm{BTC}$ is presented for port 1 (top sampling layer: $\mathrm{X}: 25 \mathrm{~cm}$; $\mathrm{Y}: 60 \mathrm{~cm}$ ) which was situated just below the water table and nearby LNAPL pool. It shows that toluene concentration starts rising after few hours and increases rapidly and then starts attenuating before reaching to a concentration of $200-230$ ppm for rapid fluctuating groundwater case. Similar trends were observed for the remaining fluctuating groundwater cases. The higher concentration in the rapid fluctuation case was due to more dissolving LNAPL pool area than general, followed by slow and stable fluctuation conditions. Likewise, BTCs of port 4 and port 7 of upper layer are presented in figure $6 b$ and $6 c$ respectively. LNAPL concentration takes 1012 hours and 20-26 hours to reach port 4 and port 7, which was $55 \mathrm{~cm}$ and $115 \mathrm{~cm}$ away from pool respectively. However, a significant difference in the final equilibrium concentration (plateau) was observed amongst different groundwater table fluctuation cases. At this stage the supply from the source and the out flux at the observed down-gradient port (port 7) was reaching to an equilibrium condition. A decreasing trend in the equilibrium concentration was observed as plume moves from up gradient location (port 1) to down-gradient locations (Port 4/7) which represents the dependency of biodegradation rate on dissolved LNAPL concentration. In general, the equilibrium concentration of toluene in earlier studies was found quite nearby to its dissolution limit. In this study, the observed concentration of toluene was not able to reach the maximum solubility value of toluene because of (a) limited contact (watertoluene) time of opportunity, (b) the concurrent biodegradation of the dissolved LNAPL in sand tank setup. The study shows that more than $150 \mathrm{ppm}$ dissolved LNAPL concentration was found to start inhibiting metabolic actions of microbes causing lower degradation rates then its 
potential rate. Similarly, a concentration less than $100 \mathrm{ppm}$ provides insufficient carbon sources to microbes resulting in comparatively low biodegradation rate of toluene. The optimal biodegradation rate was found in plume area having concentrations ranges from 120-150 ppm, especially under general groundwater condition. While biodegradation rate become quite slow at port 1 due to high dissolved LNAPL concentration (>150 ppm) and causes toxicity to potential microbes. The biodegradation rate in upper layer was accelerated by high diffusion of oxygen from head space by fluctuating groundwater table.

Likewise, the dissolved LNAPL concentrations are presented in figures 7a-c for ports 8, 11 and 14 situated in bottom layer. Figure 7a shows that the dissolved LNAPL plume takes 10-12 hours to reach at port 8 , which is at $30 \mathrm{~cm}$ downward from the pool. At port 8 , there is very less difference in equilibrium concentrations as compared to port 1 . Whereas, a large difference was found in equilibrium concentration of port 11 (Figure 7b) and port 14 (Figure 7c) in comparison to port 8 (Figure 7a). This seems due to high biodegradation rates at port 11 as compared to port 8 , even the port 11 is situated in bottom layers where background oxygen level is low.

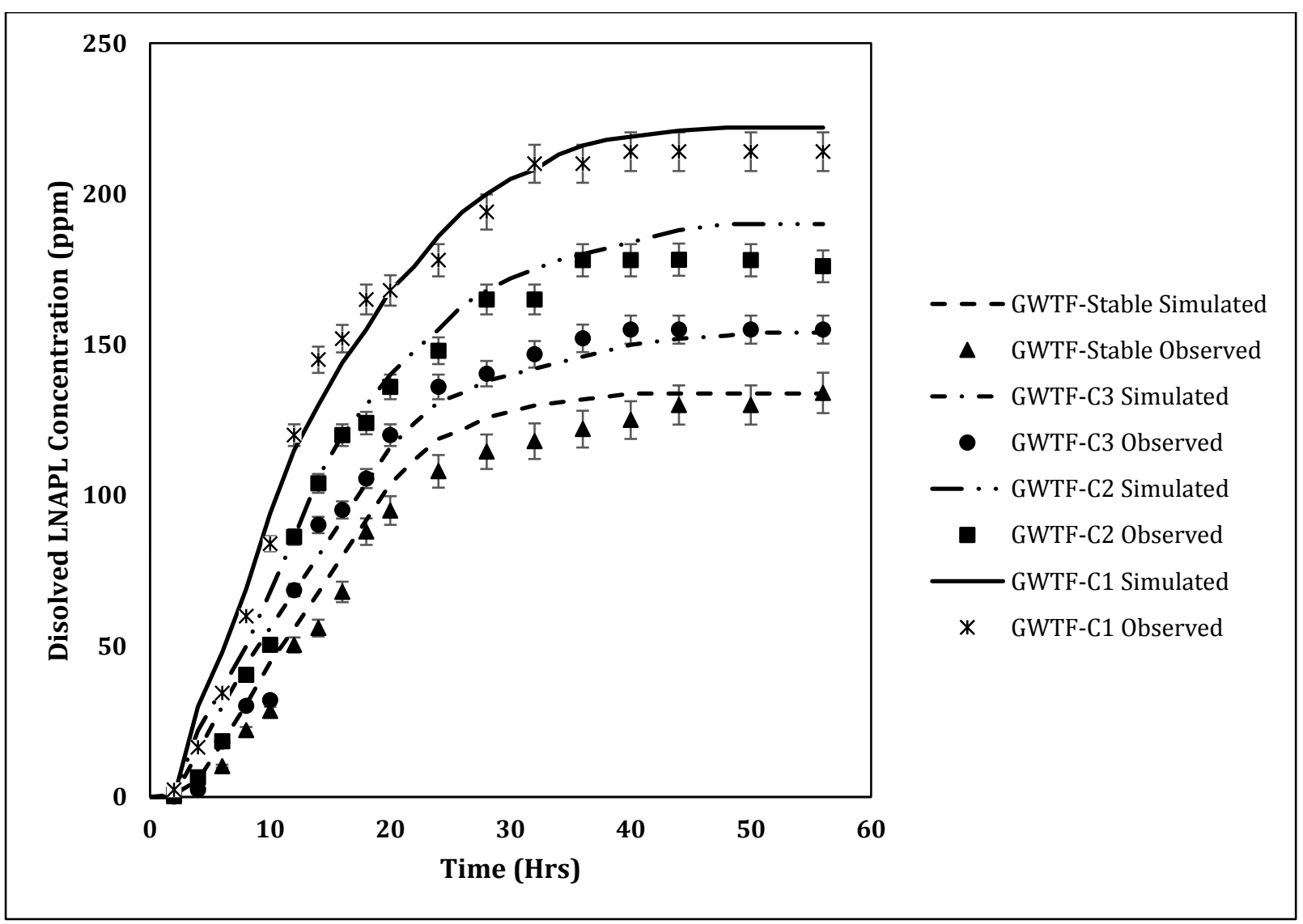


442

443

444

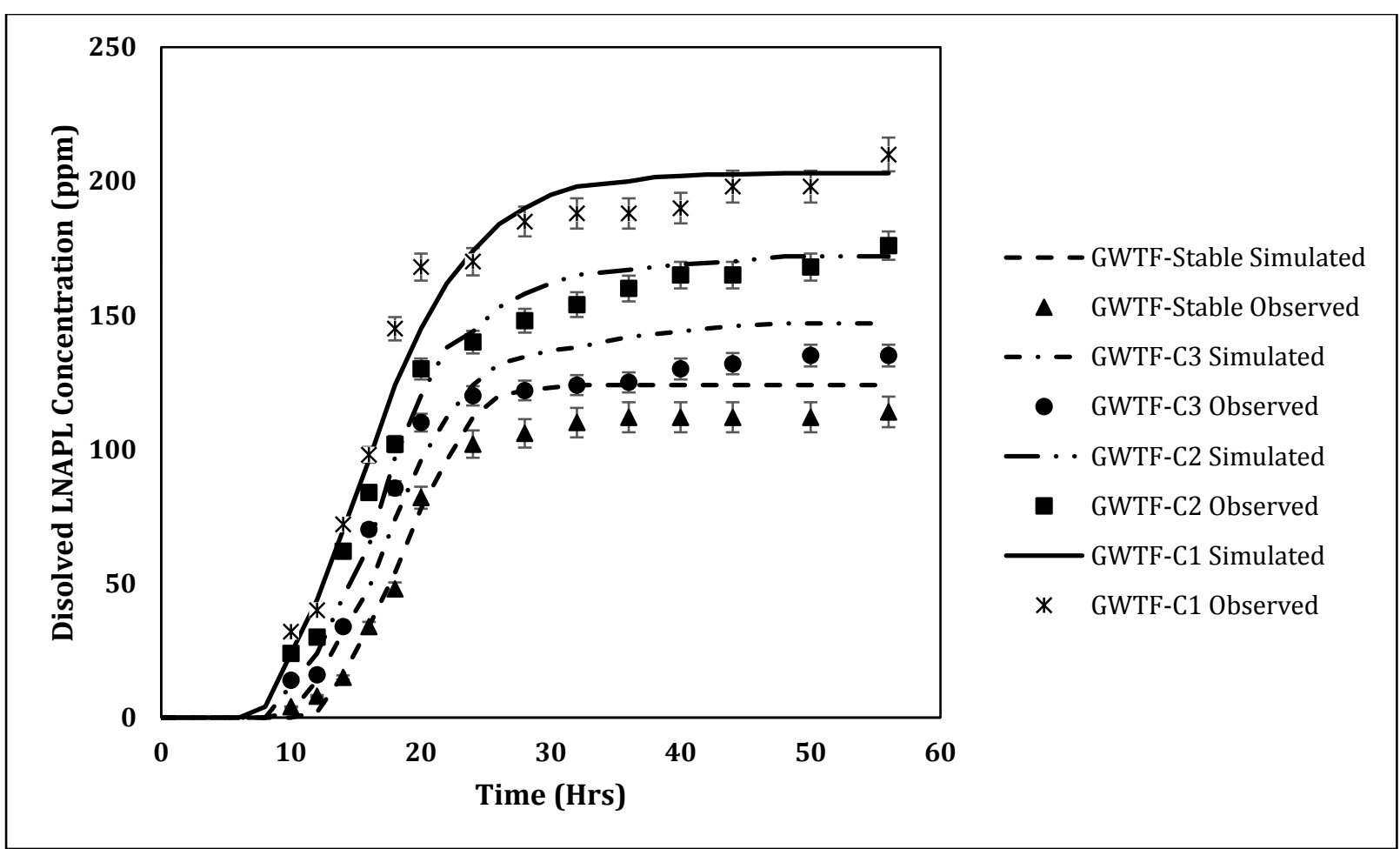

(b) Port 4: X:80; Y60

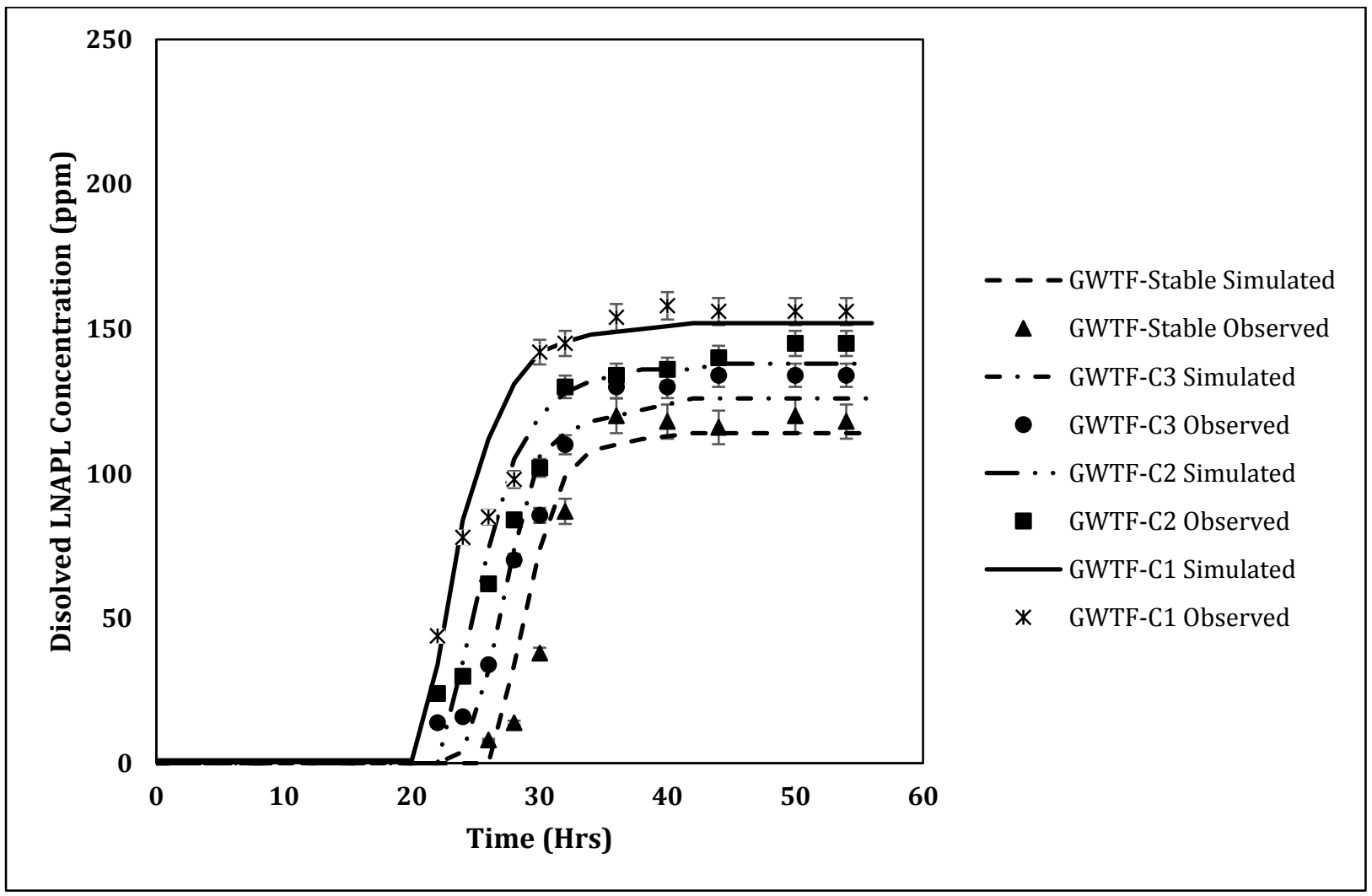

(c) Port 7: X:140; Y60

Figure 6: BTCs of (a) port 1, (b) port 4 and (c) port 7 under stable and fluctuating groundwater table conditions. 


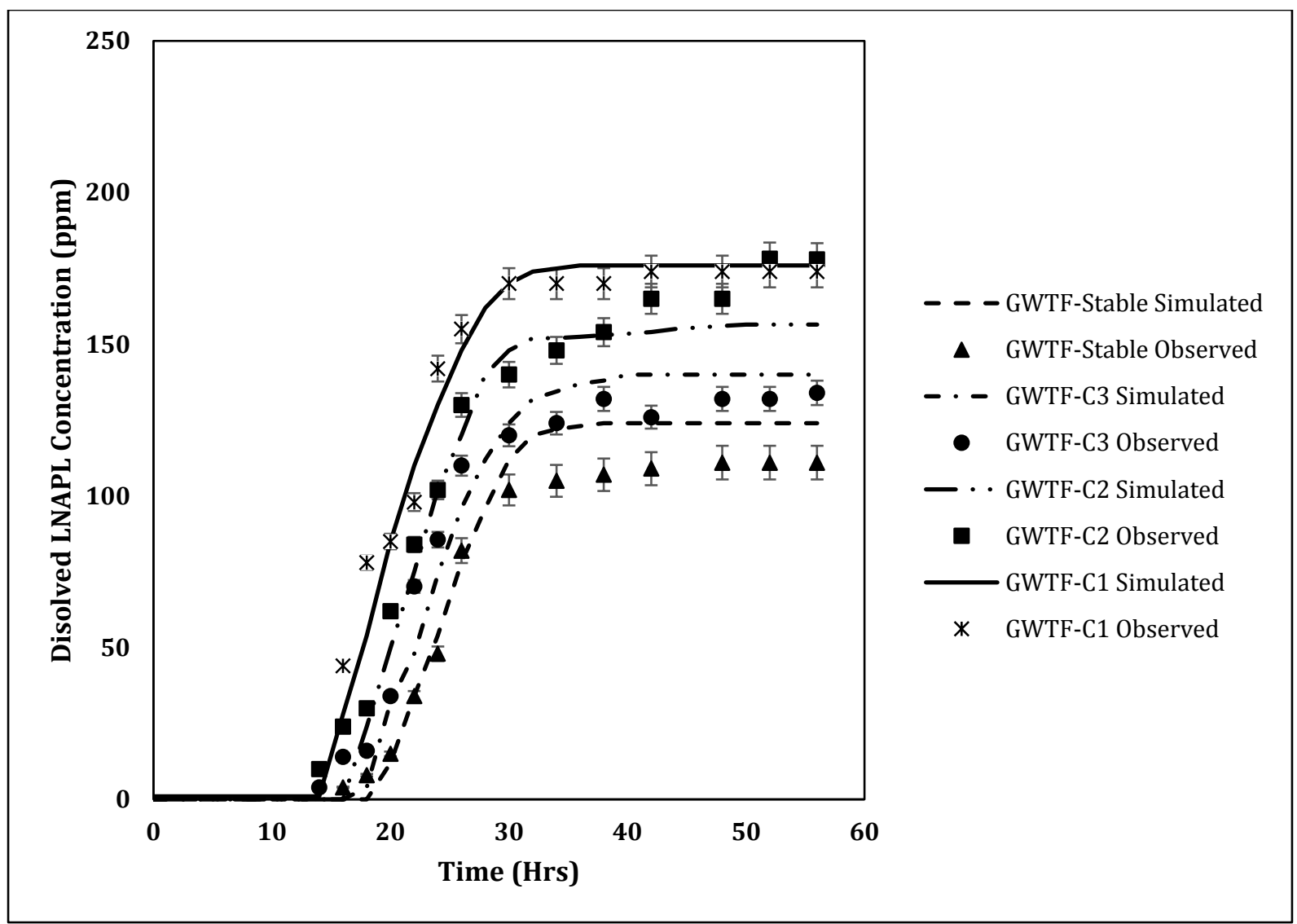

(a) Port 8: X:25; Y30

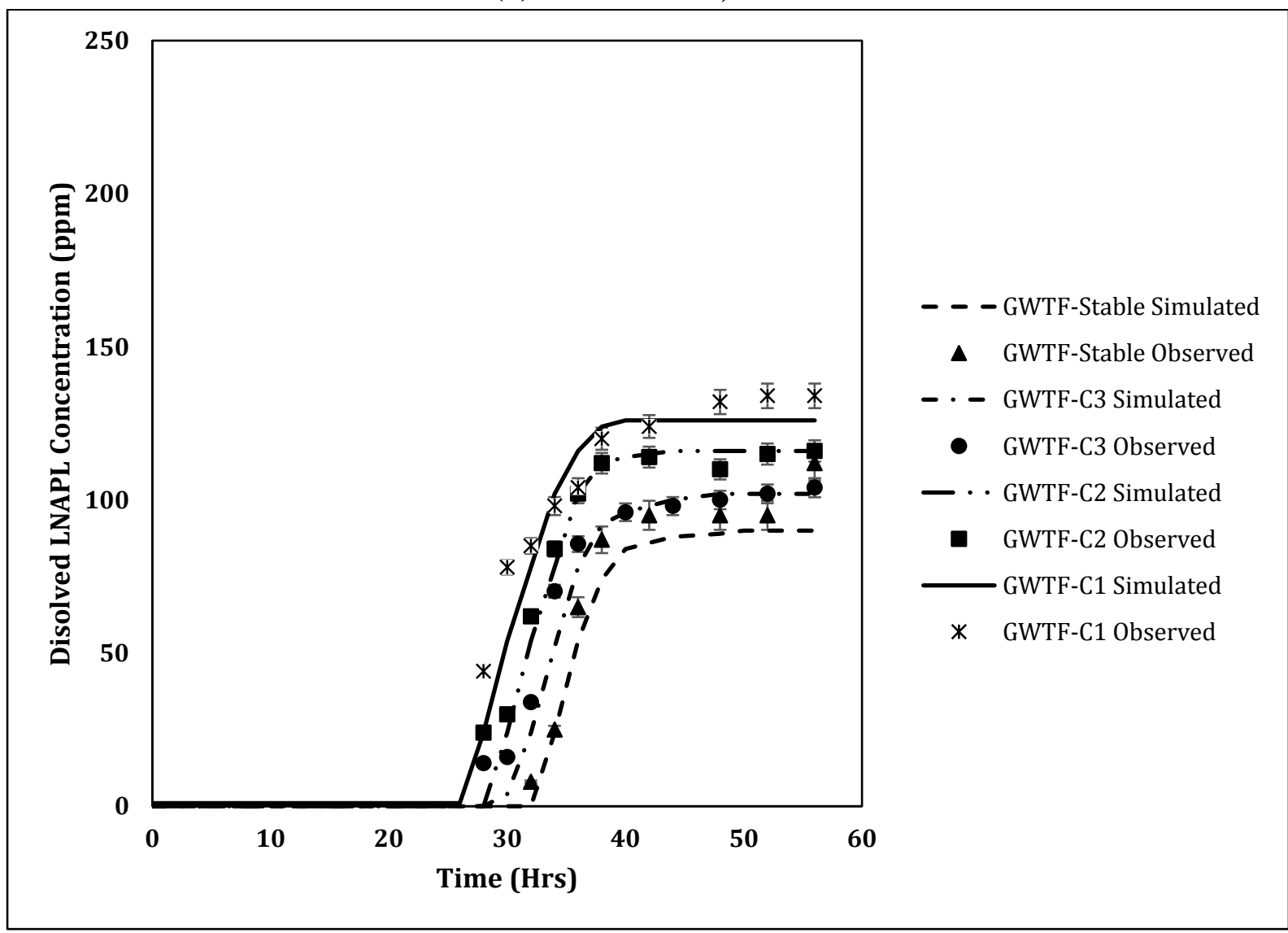

(b) Port 11: X:80; Y30 


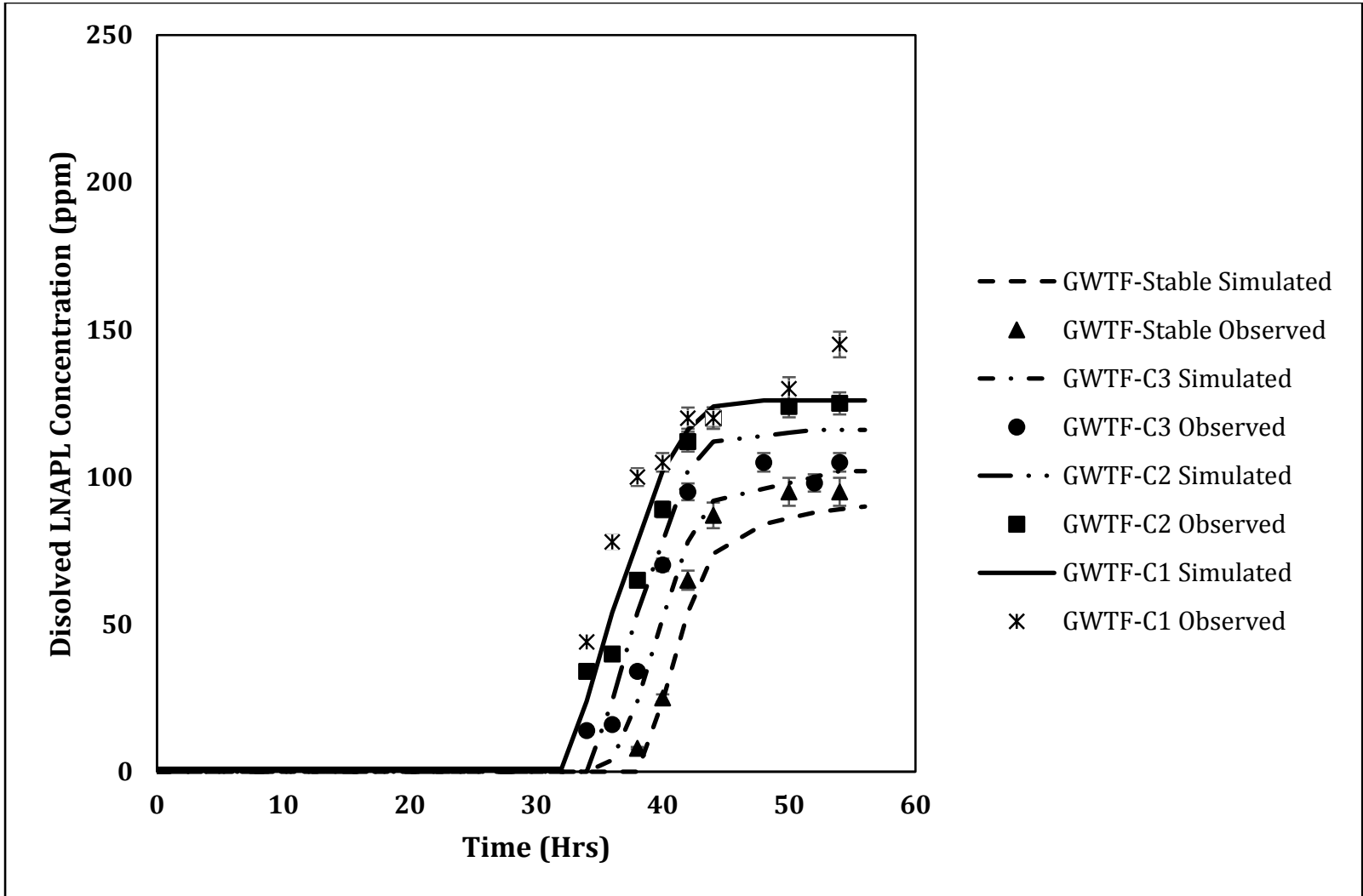

(c) Port 14: X:140; Y30

Figure 7: BTCs of (a) port 8, (b) port 11 and (c) port 14 under stable and fluctuating groundwater table conditions.

The experimentally observed dissolved LNAPL concentrations isolines are plotted as a function of space in figures 8a-d. These concentration isolines were plotted using experimentally measured data from all sampling ports (port1-14) including ports situated opposite to flow directions (port RP1-RP2). The objective of these isolines plot is to present different concentration zone originated from LNAPL pool under different selected groundwater table conditions. Figure 8 a represents concentration isolines originated from large LNAPL pool having $15.81 \mathrm{~cm}$ under rapid groundwater table fluctuation condition. Thus, large dissolved plume was created with a concentration ranges from 120-160 ppm in initial 12 hours and later reaches up to $200 \mathrm{ppm}$ nearby the pool location. A large area covered by high concentration i.e. greater than $150 \mathrm{ppm}$ causes toxicity to potential microbes and thus low biodegradation rate was observed in this case. Thus, a closely spaced isolines were observed in rapid fluctuating groundwater conditions. Whereas, figure $8 \mathrm{~b}$ represented isolines of dissolved plume originated from a pure phase LNAPL pool of characteristic length of 14.15 $\mathrm{cm}$ under general groundwater table fluctuation condition. In this case, the dissolved plume 
474 concentration ranges 110 ppm-140 ppm in initial 12 hours and continuously increases upto 160

475 ppm. Less concentration (20ppm) of dissolved plume under general groundwater table 476 fluctuation condition was due to smaller LNAPL pool length then the rapid case. Thus, in 477 general groundwater table fluctuation case, a large area covered by 130-150ppm concentration 478 LNAPL plume become carbon source to potential microbes and causes enhanced 479 biodegradation rates. Similar trends were observed in case of slow groundwater table 480 fluctuation condition as presented in figure 8c. While, comparatively small dissolved LNAPL 481 plume (figure 8d) having less concentration (i.e. range of $70 \mathrm{ppm}-100 \mathrm{ppm}$ in initial 12 hours 482 and 80-120 ppm in 56 hours) was observed in case of stable groundwater case.

483 In this study, the concentration isolines clearly show the fast transport of dissolved 484 plume in horizontal direction than its transverse movement under stable and fluctuating 485 groundwater conditions. The horizontal spreading of plume was due to advection dominated 486 flow of the dissolved toluene originating from large contact area between LNAPL pool and 487 water. Dissolved LNAPL plume movement in opposite direction of groundwater flow driven 488 by diffusive flux is comparative very slow. Whereas, the expansion of dissolved LNAPL plume 489 in the vertical direction under fluctuating groundwater shows the crucial role of dispersive flux. 490 The diffusive flux of the dissolved LNAPL can play a crucial role in LNAPL movement under 491 stable groundwater regimes. 


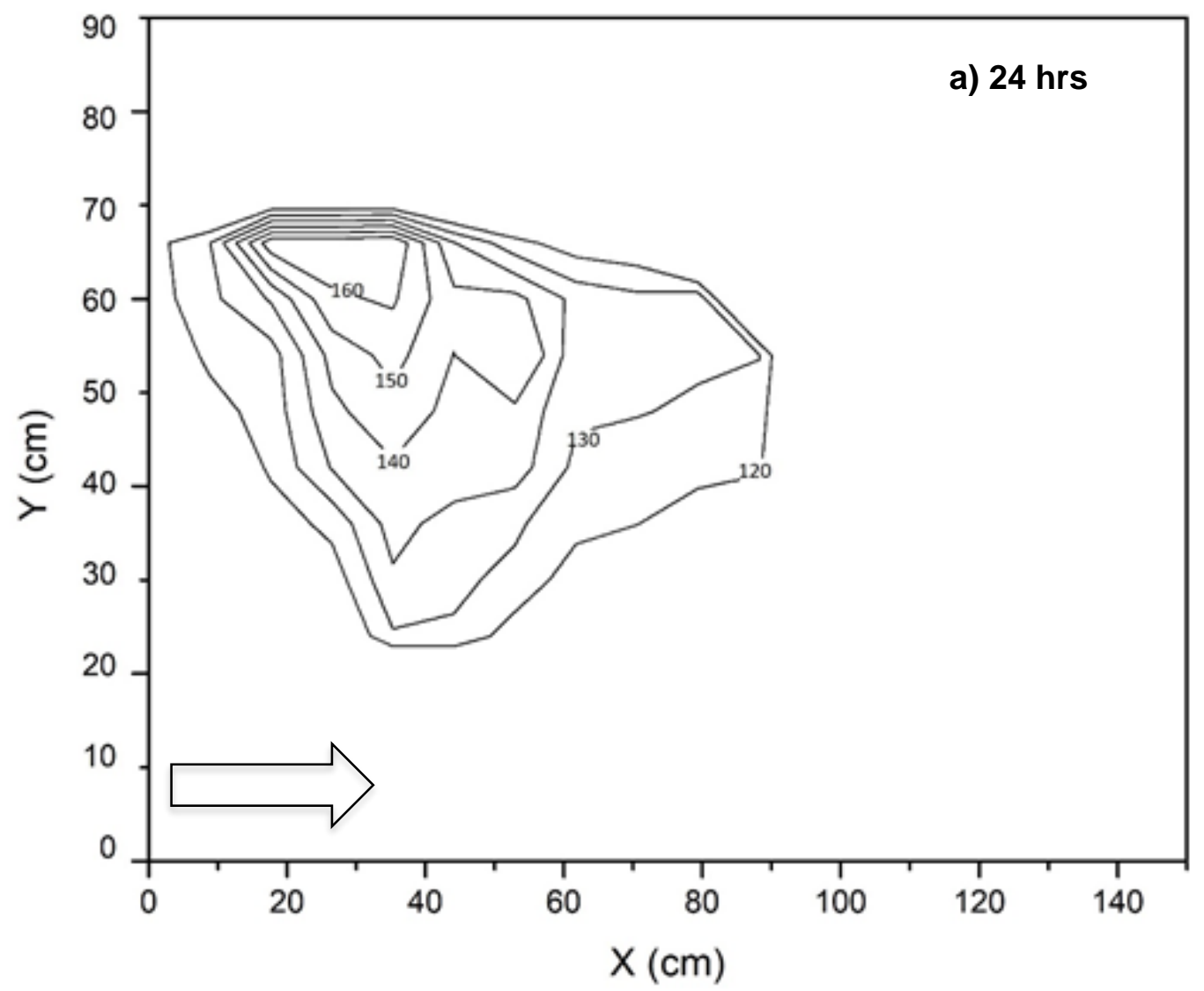

493

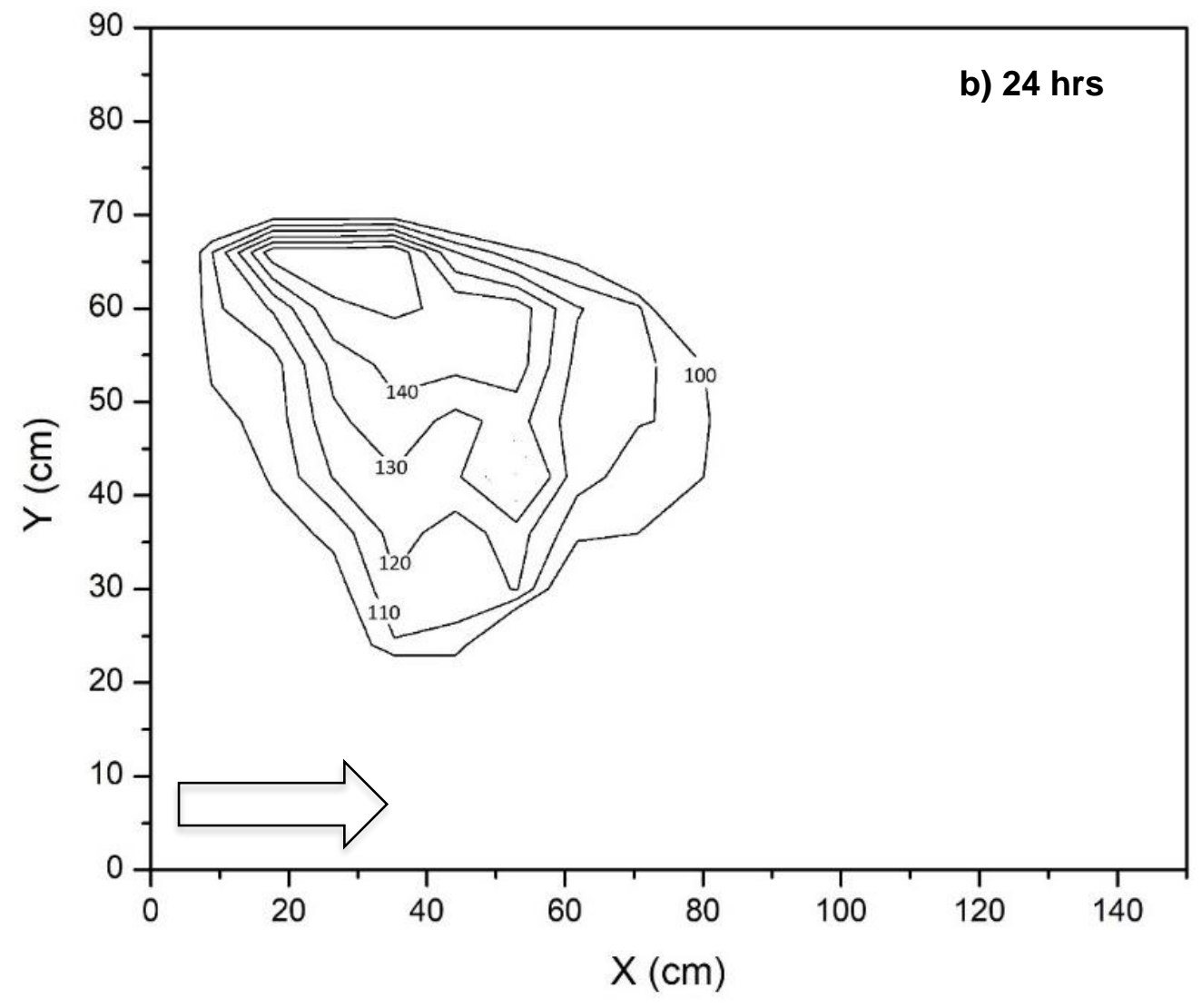




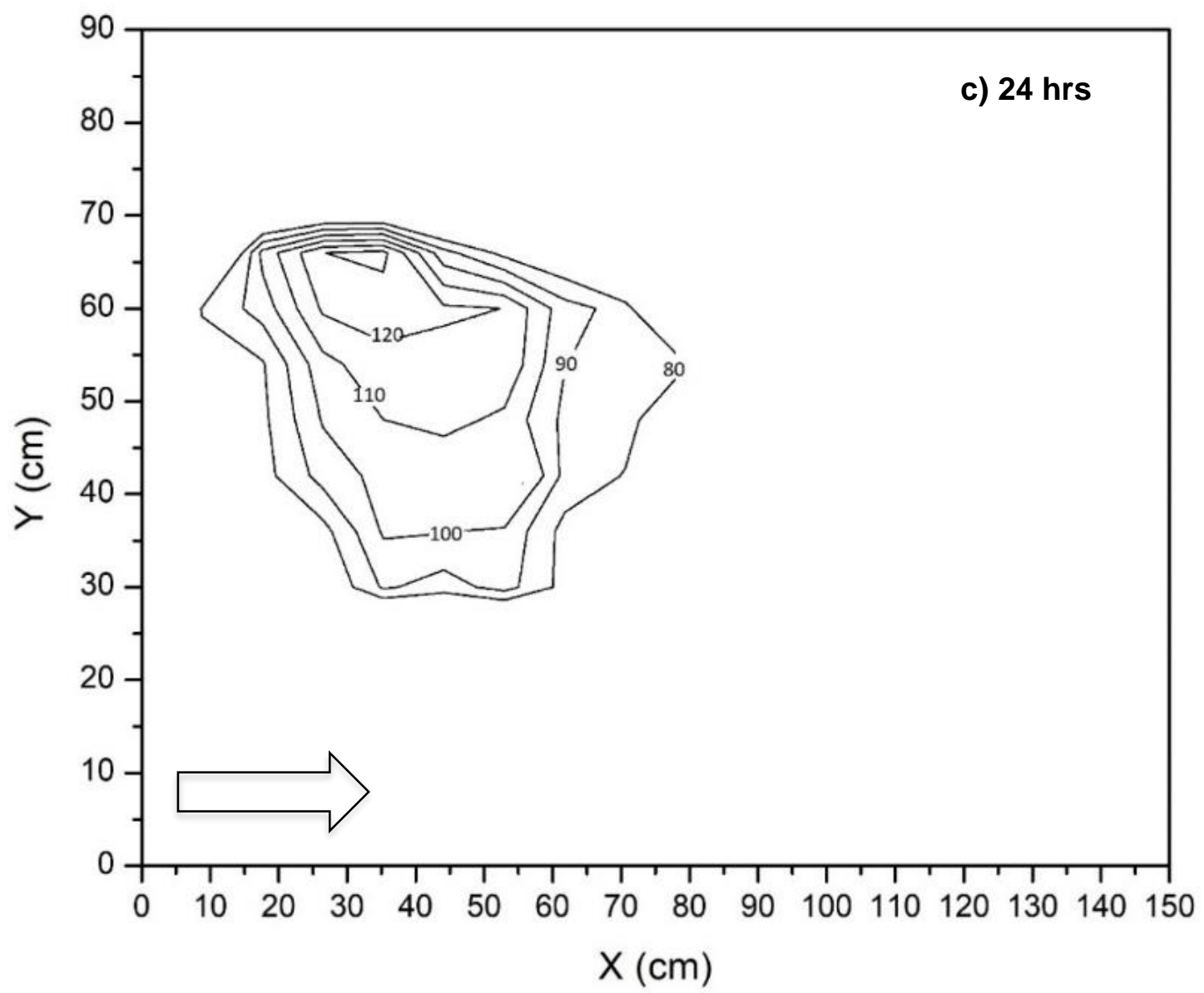

495

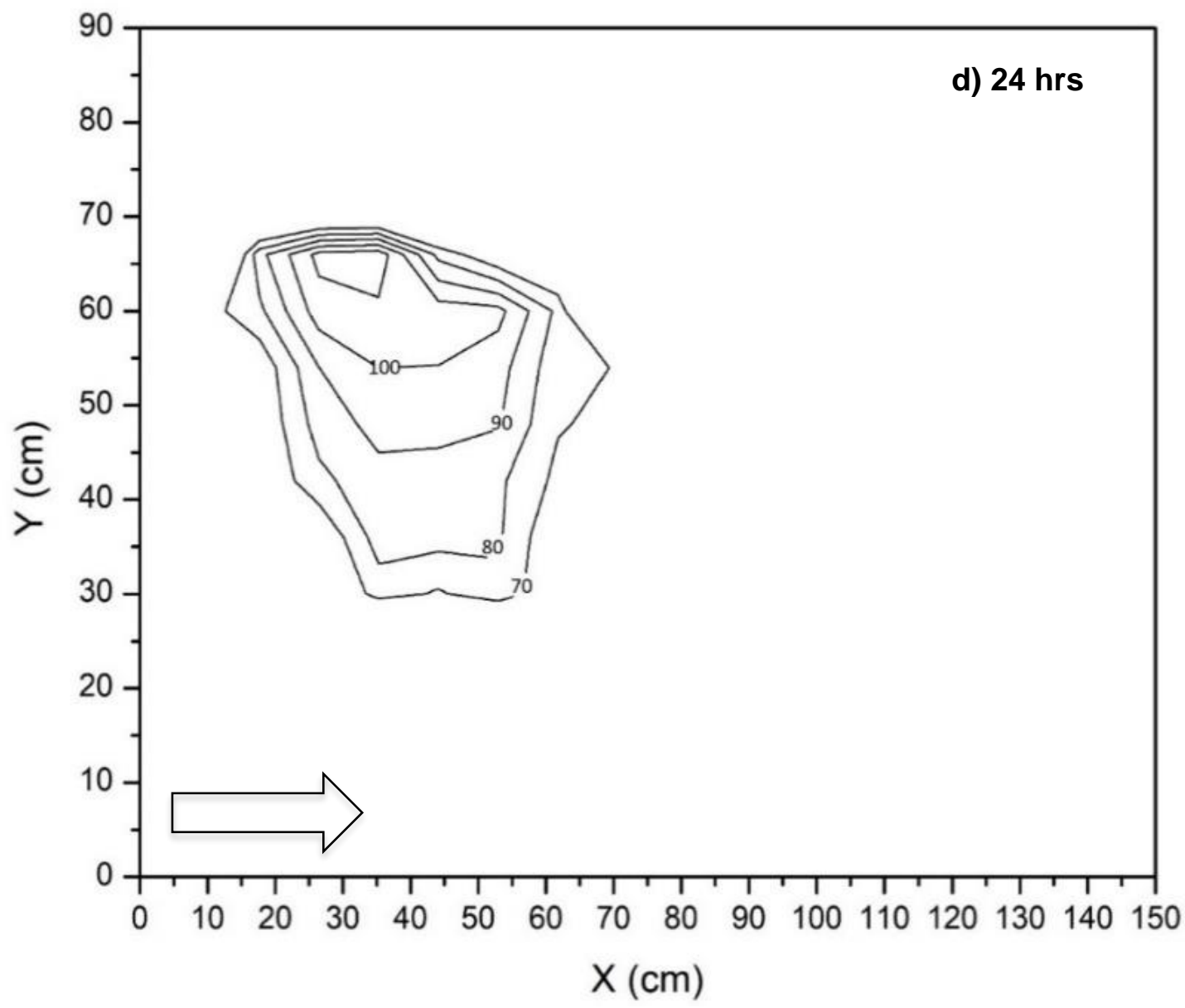




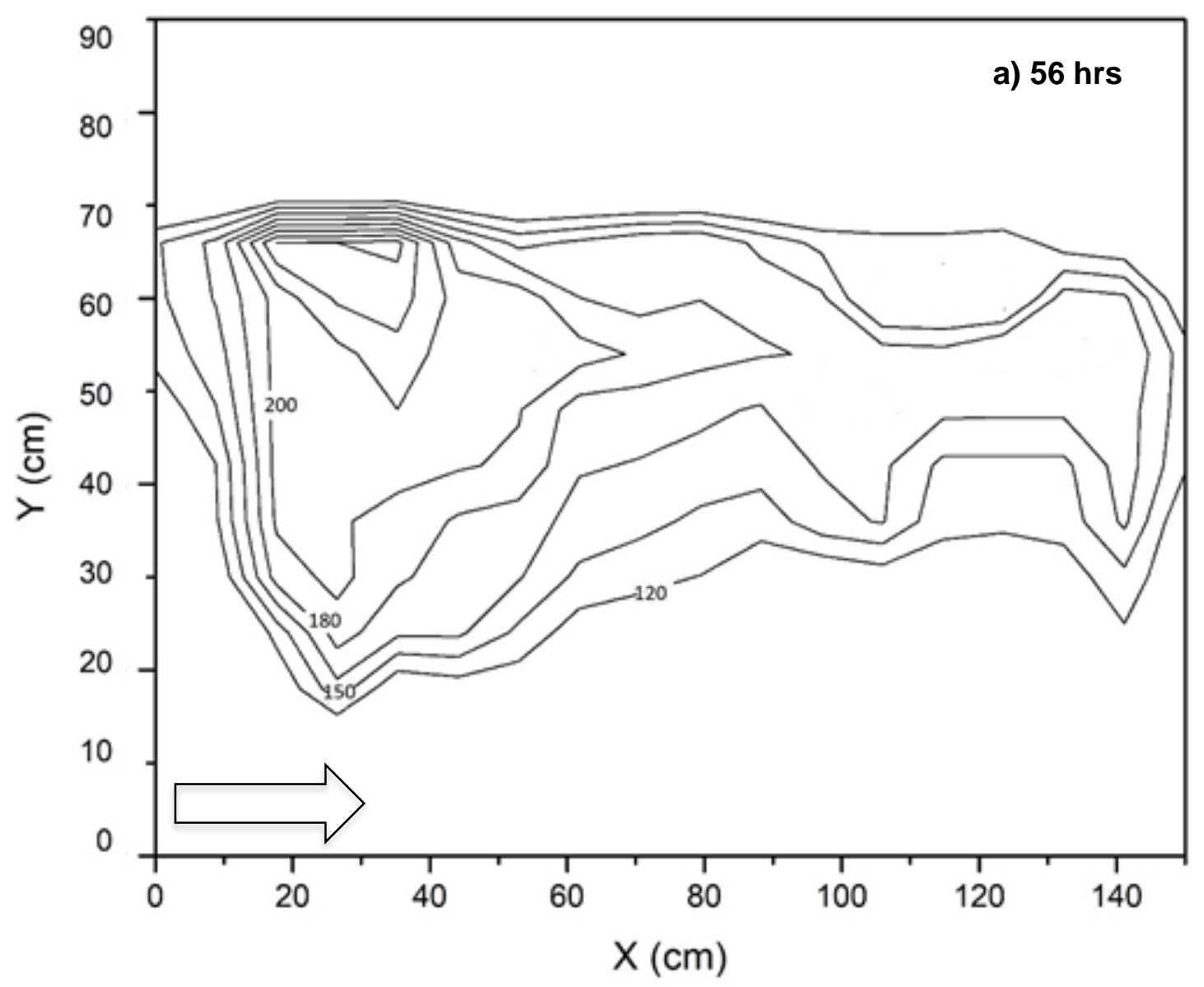

497

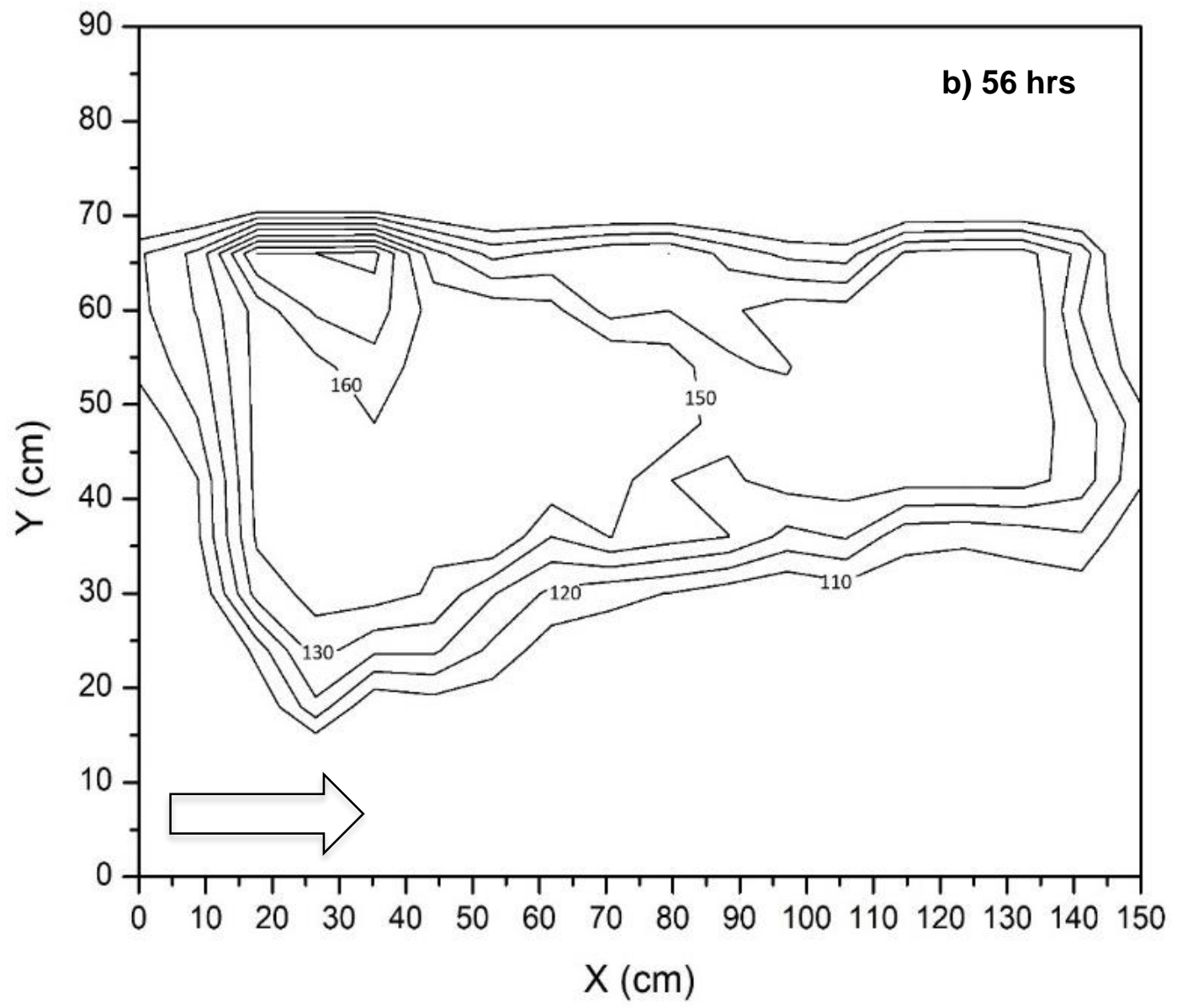




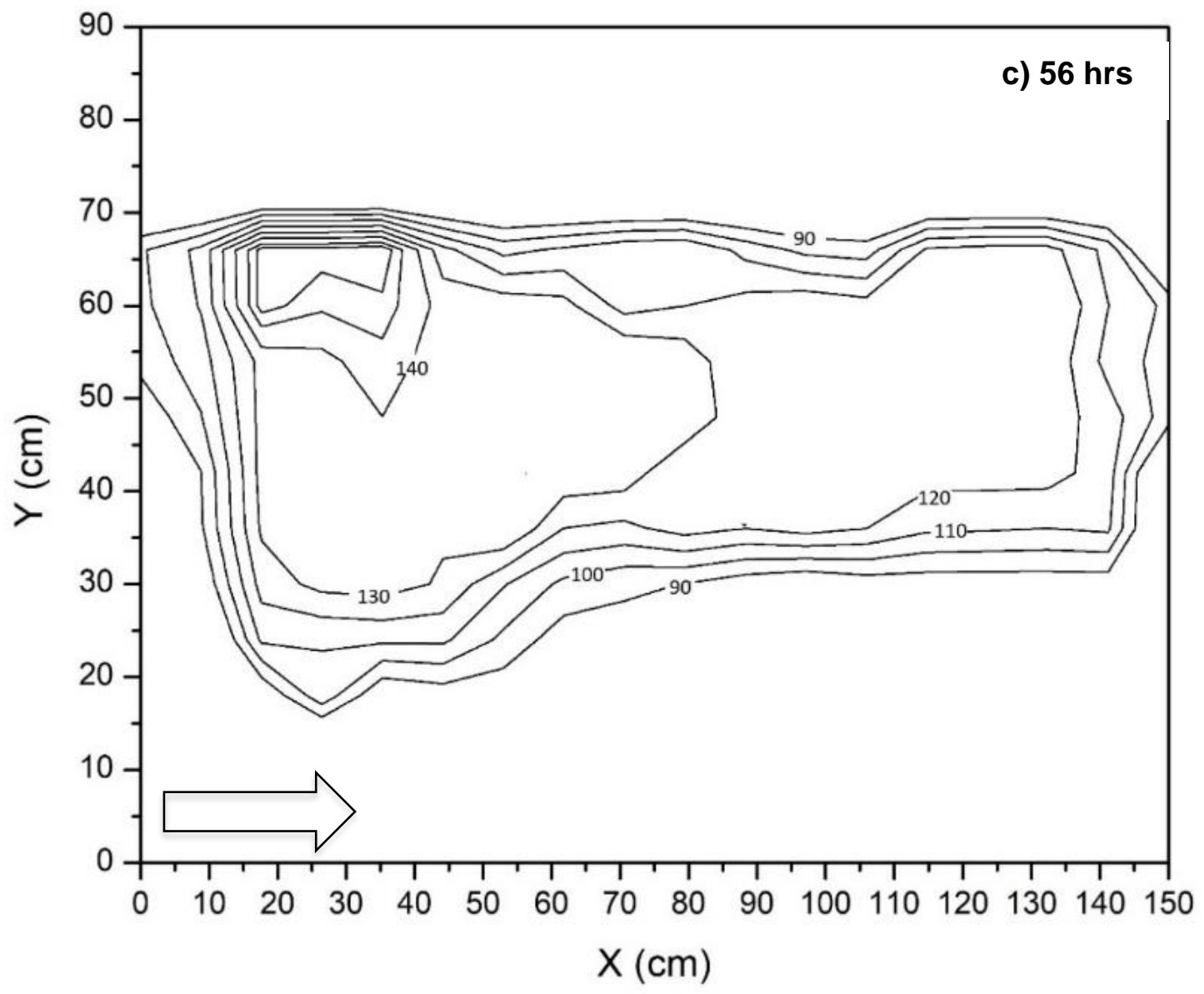

499

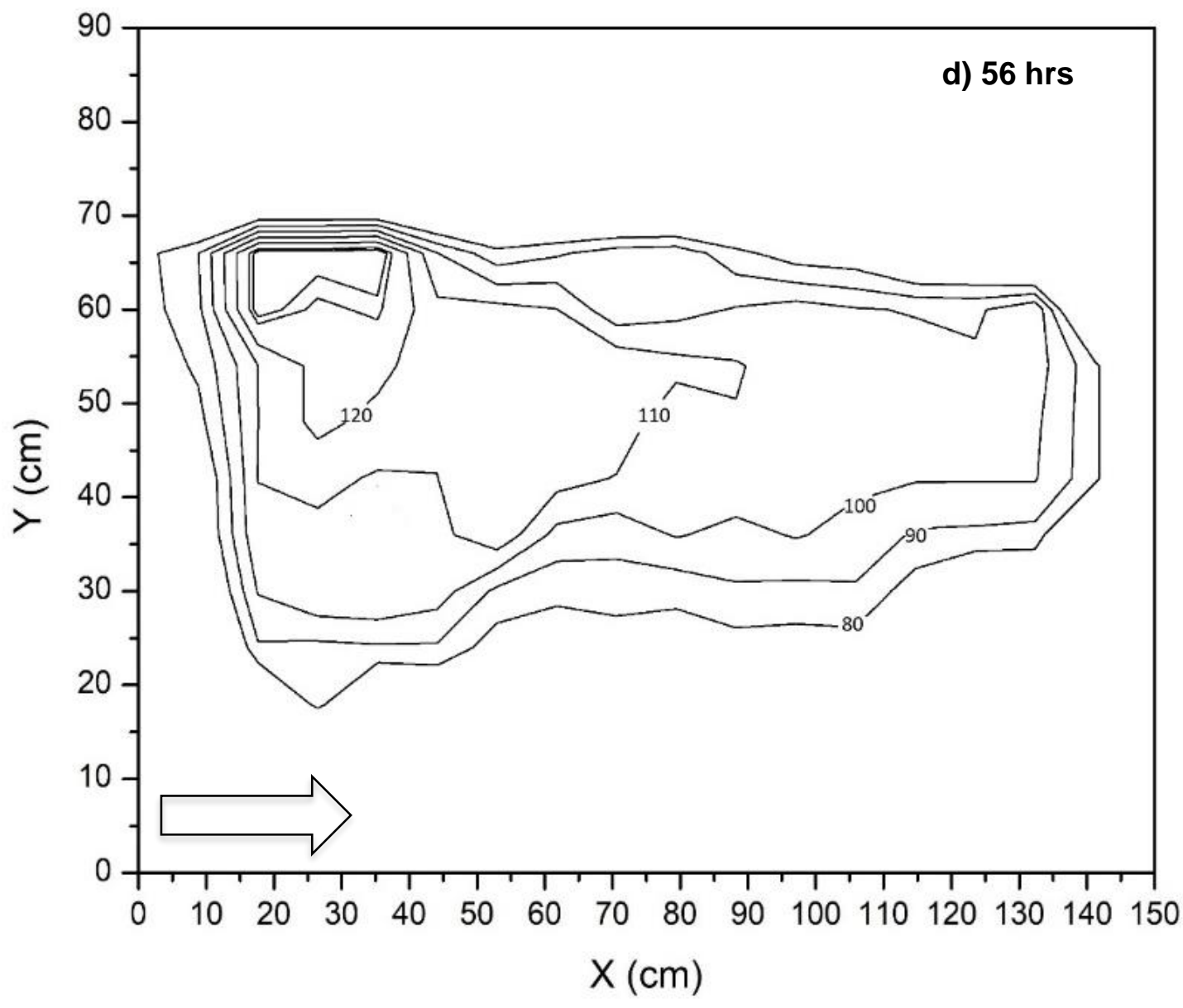


Figure 8: Concentration isolines presenting the extension of dissolved LNAPL plume originated from pure phase source under a) rapid, b) general, c) slow and d) stable groundwater table fluctuation cases.

\subsection{Biodegradation under different groundwater table fluctuation conditions}

Biodegradation rate of dissolved LNAPL plume originated from pooled LNAPL under stable and fluctuating groundwater conditions was also investigated. For this purpose, spatial biodegradation rates were estimated for port 1 and port 4 of upper sampling layer and port 8 and 14 of lower sampling layer. In Figure 9, the biodegradation rates were estimated using corresponding values of equilibrium concentration of upward port and subsequent downward port. Figure 9a presents biodegradation rate of port 4 situated $55 \mathrm{~cm}$ away from LNAPL pool. At this location, biodegradation rates of $0.5 \mathrm{ppm} / \mathrm{hour}, 0.55 \mathrm{ppm} / \mathrm{hour}, 0.26 \mathrm{ppm} / \mathrm{hour}$, and 0.13 $\mathrm{ppm} / \mathrm{hour}$ were observed for dissolved LNAPL zone with the concentration of $180 \mathrm{ppm}, 150$ ppm, 120 ppm, and 100 ppm under rapid, general, slow and stable groundwater table condition, respectively.

The biodegradation rate was found comparatively low in case of rapid fluctuation than general fluctuation because of large high concentration (>150 ppm) region which causes toxic effects on potential microbes lies in this region. While, the high biodegradation rate in case of general than slow and stable groundwater fluctuation conditions proves the dependency of microbes on dissolved LNAPL concentrations. Figure $9 \mathrm{~b}$ represents biodegradation rates for port 7 of upper layer having dissolved LNAPL concentration in the range of $100 \mathrm{ppm}-150 \mathrm{ppm}$. Similarly, Figure 9c and 9d shows the biodegradation rates for port 8 and port 14 of lower layer respectively. Comparatively low biodegradation rates were observed in lower layer ports under stable groundwater conditions, even if the dissolved LNAPL concentration was in the optimum range of $100 \mathrm{ppm}-150 \mathrm{ppm}$. These low biodegradation rate at lower ports was due to comparatively less populated potential microbes due to low oxygen level. While, the biodegradation rates were also increases at lower port in case of fluctuating groundwater conditions. These accelerated biodegradation rate can attribute to the fact that the additional oxygen to background level was added due to fluctuation in water table, which enhance the microbial growth.

Microbial population was also counted using standard plate count method for periodically collected soil-water samples from port 1 and port 7 of upper layer and port 8 and port 14 of lower layer. The estimated CFU of collected soil-water samples were listed in table 4. Initially, microbial count of $216.2-258 \times 10^{4} \mathrm{CFU} / \mathrm{mL}$ and $142.5-147.2 \times 10^{4} \mathrm{CFU} / \mathrm{mL}$ was 
observed at upper and lower layer respectively. In GWTF-C1 case, the microbial count at port 1 increases upto $305 \times 10^{4} \mathrm{CFU} / \mathrm{mL}$ in 24 hours and then decreases to $78 \times 10^{4} \mathrm{CFU} / \mathrm{mL}$ in 56

537 hours. Similarly, at port 7, overgrowth was recorded after 24 hours thereafter decreases to $224 \times 10^{4} \mathrm{CFU} / \mathrm{mL}$ in 56 hours.

The enhanced microbial growth was observed as dissolved LNAPL concentration reached around 140-150 $\mathrm{ppm}$ at this location which provides sufficient carbon source to 541 microbes. However, when the dissolved LNAPL concentration reaches higher than $150 \mathrm{ppm}$, 542 it become toxic to microbial community. Increasing microbial count was recorded at both port 543 of top layer due to optimum dissolved LNAPL concentration and sufficient oxygen level in 544 general and slow groundwater fluctuation. Microbial count was recorded very low at port 14 545 of lower layer due to low concentration of dissolved LNAPL and insufficient oxygen level 546 under all groundwater table conditions. Growing population of the microbial community at 547 petroleum hydrocarbon-contaminated groundwater observed due to seasonal groundwater level 548 fluctuations by Zhou et al. (2015). Such microbial analysis may help to implement nutrient and 549 or electron acceptor plan to enhance petrochemical degrading microbes.

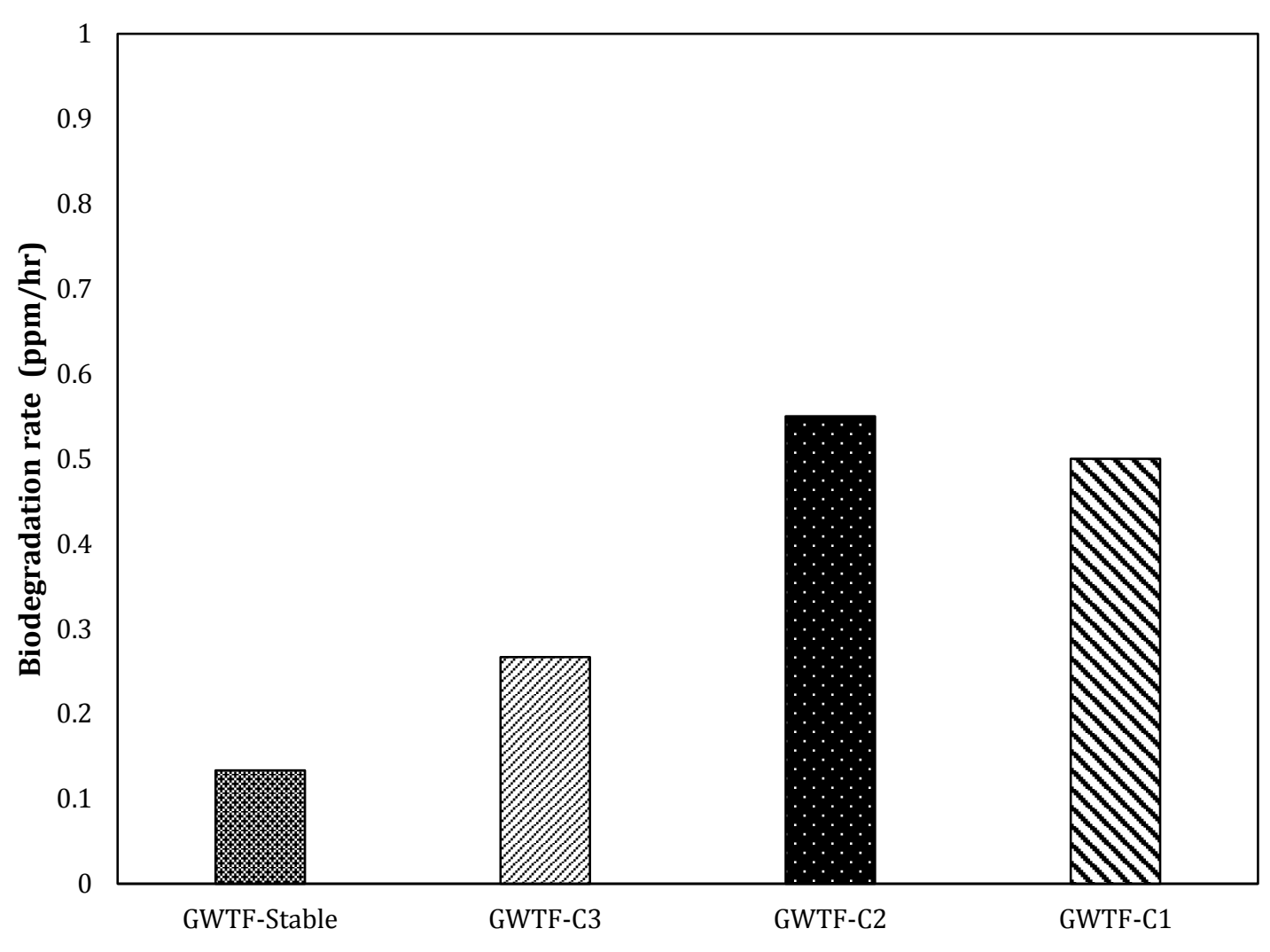




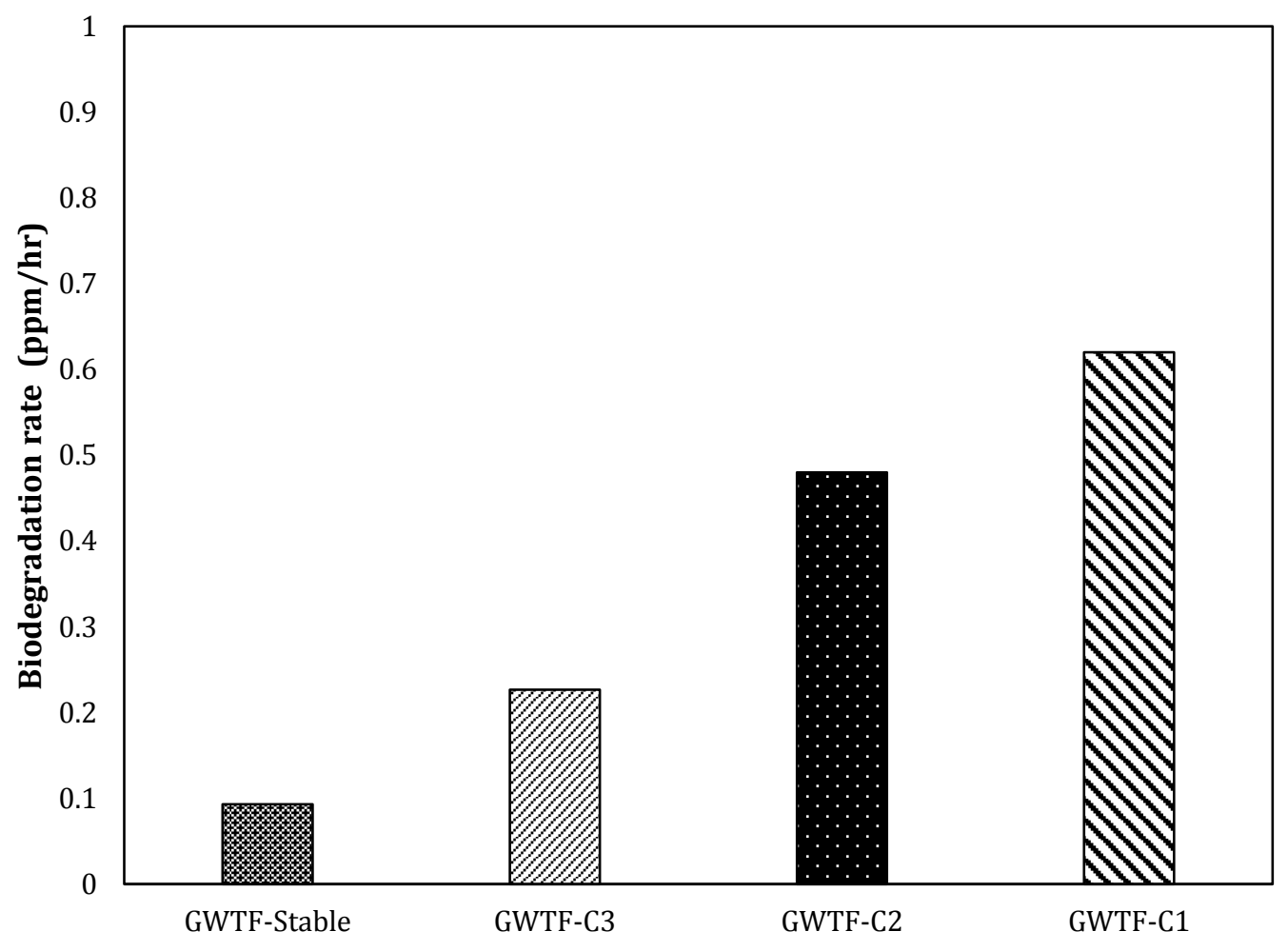

556

(b)

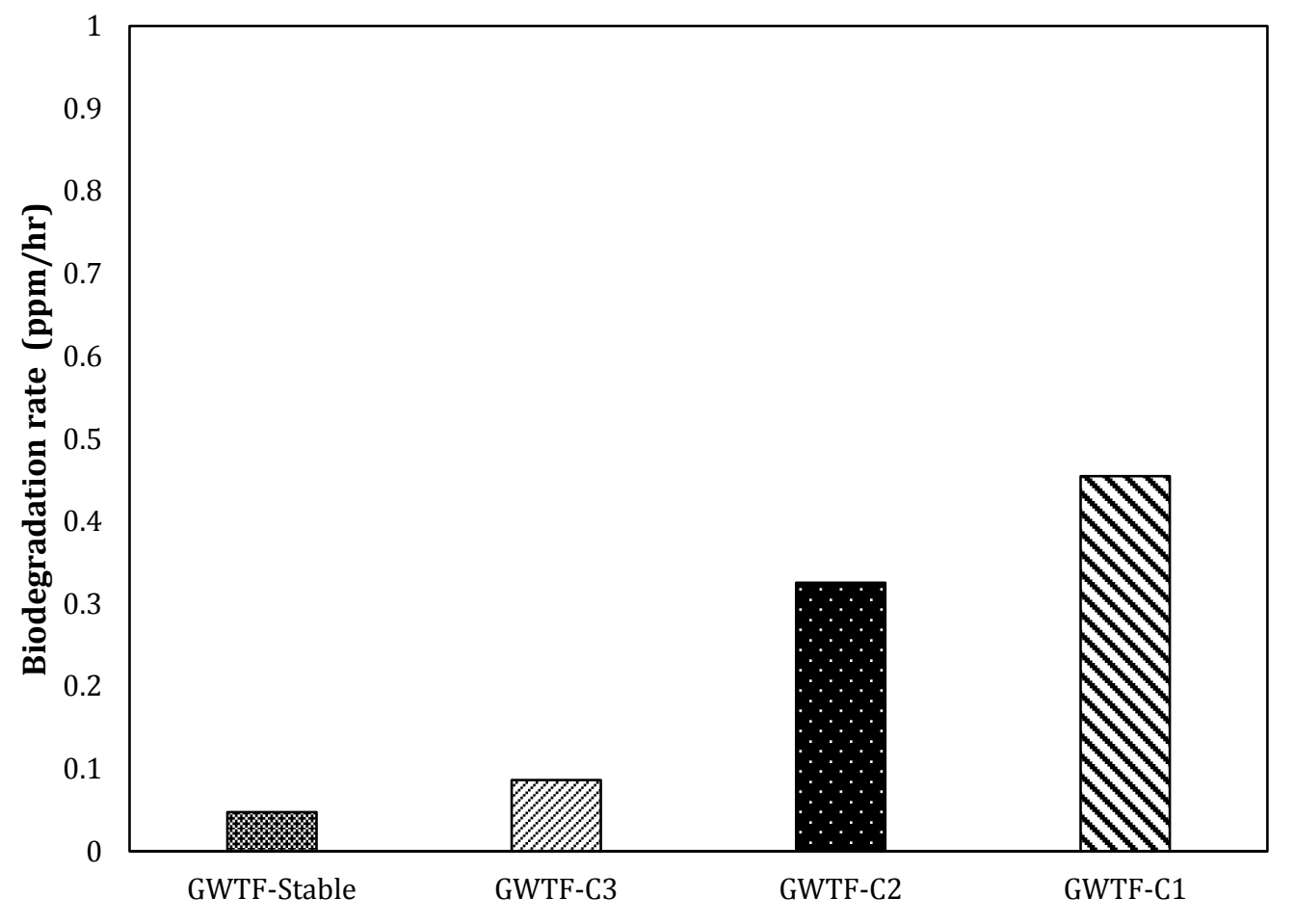




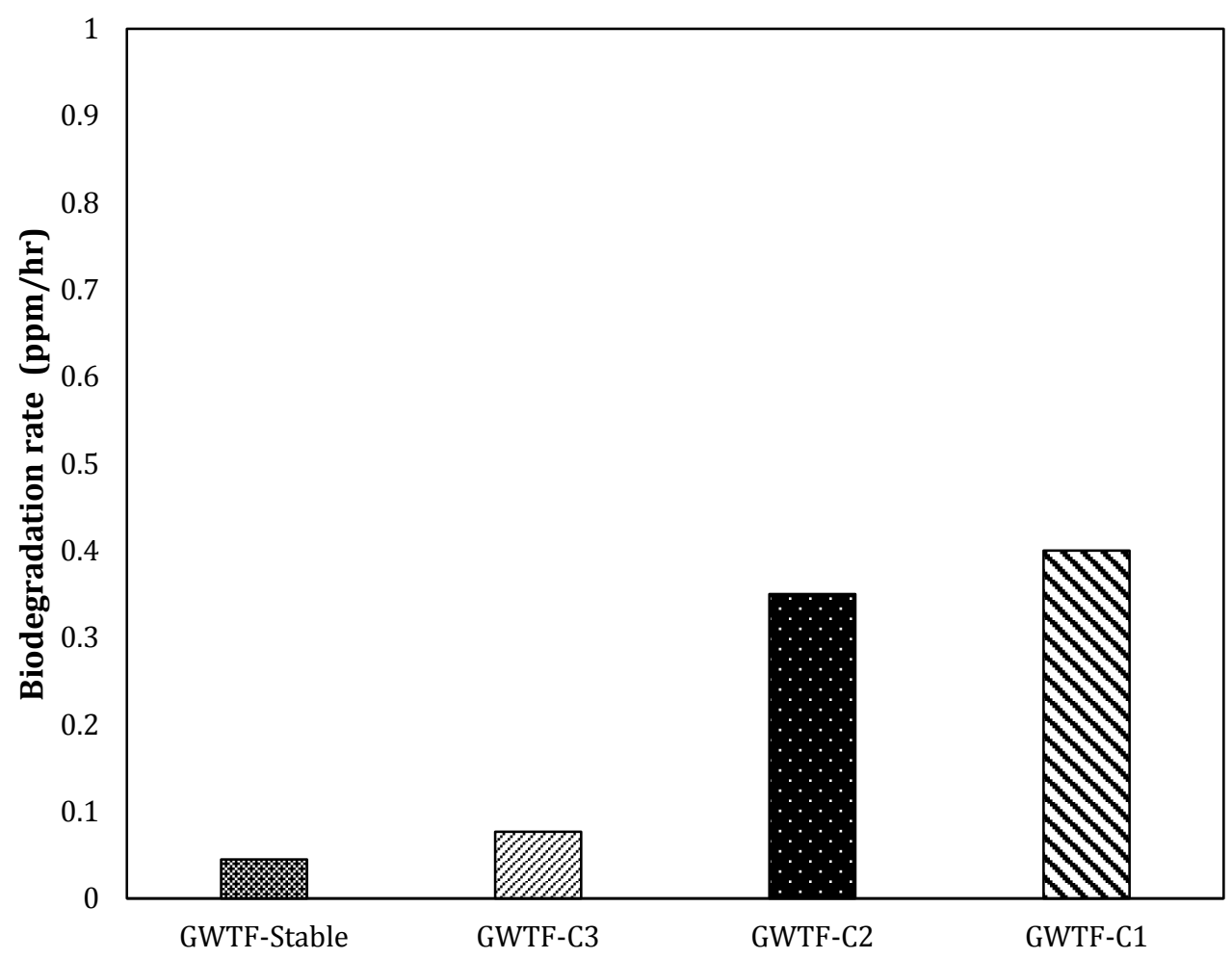

563 Figure 9: Biodegradation rates under stable and fluctuating groundwater conditions observed at (a) port 1 and (b) port 7 of upper sampling layer and (c) port 8 and (d) port 14 of bottom sampling layer of 2D sand tank setup.

566

Table 4. Microbial population count of samples collected from the experimental setup under different groundwater table conditions.

569

\begin{tabular}{|c|c|c|c|c|c|c|c|c|c|c|c|c|}
\hline \multirow[t]{3}{*}{ Condition } & \multicolumn{3}{|c|}{ Port 1} & \multicolumn{3}{|c|}{ Port 7} & \multicolumn{3}{|c|}{ Port 8} & \multicolumn{3}{|c|}{ Port 14} \\
\hline & \multicolumn{3}{|c|}{$10^{4} \mathrm{CFU} / \mathrm{mL}$} & \multicolumn{3}{|c|}{$10^{4} \mathrm{CFU} / \mathrm{mL}$} & \multicolumn{3}{|c|}{$10^{4} \mathrm{CFU} / \mathrm{mL}$} & \multicolumn{3}{|c|}{$10^{4} \mathrm{CFU} / \mathrm{mL}$} \\
\hline & Ohr & $24 \mathrm{hr}$ & $48 \mathrm{hr}$ & Ohr & $24 \mathrm{hr}$ & $48 \mathrm{hr}$ & $\mathrm{Ohr}$ & $24 \mathrm{hr}$ & $48 \mathrm{hr}$ & Ohr & $24 \mathrm{hr}$ & $48 \mathrm{hr}$ \\
\hline GWFT-C1 & 254.5 & 305 & 78 & 258.0 & $\mathrm{O}$ & 224.5 & 147.2 & 165 & 135.4 & 142.5 & 145.8 & 165 \\
\hline GWFT-C2 & 232.1 & 294.8 & 304.6 & - & 285.0 & $\mathrm{O}$ & 145 & 174.2 & 235.0 & - & 164.5 & 218 \\
\hline GWTF-C3 & 216.2 & 285.4 & 277.5 & 224.5 & 288.0 & $\mathrm{O}$ & 144.5 & 210.5 & 270.6 & - & 164.2 & 235.6 \\
\hline
\end{tabular}


575 In this study, a series of laboratory experiments and numerical modelling was performed to 576 investigate fate and transport of LNAPL originated from pure phase LNAPL pool under stable 577 and fluctuating groundwater conditions. Three different groundwater fluctuating 578 experiments representing rapid, general and slow groundwater table fluctuation scenarios 579 were conducted by raising/falling water table by $5 \mathrm{~cm}$ of magnitude in 1,2 , and 4 hours 580 respectively. Estimated pool area shows a large pure phase LNAPL pool in smear zone 581 under fluctuating groundwater conditions, resulting in accelerating dissolution rate from large LNAPL-water interphase area. Simulated and observed BTCs show high dissolved LNAPL concentration and large plume originated from large LNAPL-water interphase area

584

585

586

587

588

589

590

591

592

593

594

595

596

597

598

599

600

601

602

603

604

605 under rapid groundwater fluctuation condition. The time of arrival of plume shows that transport of dissolved LNAPL was comparatively more in case of rapid fluctuating groundwater condition. A high biodegradation rate was observed in regions having concentration ranges from 140-160 ppm of dissolved LNAPL. While, low biodegradation rates were observed for low dissolved LNAPL concentrations ( $<140 \mathrm{ppm})$ and also high concentrations (>160ppm) which fortifies the dependency on initial dissolved LNAPL concentrations. Further, microbial growth was found to be increasing as plume moves away from the LNAPL pool, which shows detrimental impact of high concentration of toluene on survival of indigenous microorganisms. Overall, this study suggest that groundwater table fluctuations significantly affects the distribution, transport, and biodegradation of the LNAPL contaminants in subsurface. The results of this study may be improved by considering subsurface heterogeneity and fractures. This study may help in design, establishment and implementation of bioremediation techniques to decontaminate LNAPL polluted sites, especially under varying subsurface conditions.

\section{Acknowledgment}

The authors are thankful to the Department of Science and Technology (DST), India for funding this research under the scheme of Ramanujan fellowship. Authors are also thankful to University Grant Commission, New Delhi to provide JRF/SRF for this study.

\section{References}


606

607

608

609

610

611

612

613

614

615

616

617

618

619

620

621

622

623

624

625

626

627

628

629

630

631

632

633

634

635

636

637

Basu, S., Yadav, B. K., and Mathur, S. 2015. Enhanced bioremediation of BTEX contaminated groundwater in pot-scale wetlands. Environmental science and pollution Research. 22(24), 20041-20049.

Brusseau, M. L., Zhang, Z., Nelson, N. T., Cain, R. B., Tick, G. R., and Oostrom, M. 2002. Dissolution of non-uniformly distributed immiscible liquid: intermediate-scale experiments and mathematical modeling. Environmental science and technology. 36(5), 1033-1041.

Cherry J.A; Parker B.L; Bradbury K.R; Eaton T.T; Gotkowitz M.G; Hart; Borchardt M.A., 2004. Role of Aquitards in the Protection of Aquifers from Contamination: A "State of the Science" Report, Published by the Awwa Research Foundation, Denver, CO 80235 3098.

Chrysikopoulos, C.V., 1995. Three-dimensional analytical models of contaminant transport from nonaqueous phase liquid pool dissolution in saturated subsurface formations. Water resource research. $31,1137-1145$.

Chrysikopoulos, C.V., Voudrias, E.A., Fyrillas, M.M., 1994. Modeling of contaminant transport resulting from dissolution of nonaqueous phase liquid pools in saturated porous media. Transport in Porous Media 16, 125-145.

Das, D. B. 2002. Hydrodynamic modelling for groundwater flow through permeable reactive barriers. Hydrological Processes, 16(17), 3393-3418.

Das, D. B., and Mirzaei, M. 2012. Dynamic effects in capillary pressure relationships for twophase flow in porous media: Experiments and numerical analyses. AIChE Journal, 58(12), 3891-3903.

Das, D. B., and Nassehi, V. 2003. Modeling of contaminants mobility in underground domains with multiple free/porous interfaces. Water Resources Research, 39(3).

Dempster, H.S., Sherwood-Lollar, B., Feenstra, S., 1997. Tracing organic contaminants in groundwater: a new methodology using compound-specific isotopic analysis. Environmental science and technology. 31, 3193-3197.

Dobson, R., M.H. Schroth, and J. Zeyer. 2007. Effect of water-table fluctuation on dissolution on and biodegradation of a multi-component, light nonaqueous-phase liquid. Journal of contaminant hydrology. 94, 235-248.

Herzyk, A., Fillinger, L., Larentis, M., Qiu, S., Maloszewski, P., Hünniger, M., Schmidt, S.I., Stumpp, C., Marozava, S., Knappett, P.S. and Elsner, M., 2017. Response and recovery 
638

639

640

641

642

643

644

645

646

647

648

649

650

651

652

653

654

655

656

657

658

659

660

661

662

663

664

665

666

667

668

of a pristine groundwater ecosystem impacted by toluene contamination-A meso-scale indoor aquifer experiment. Journal of contaminant hydrology. 207, 17-30.

Illangasekare, T.H., E. J. Armbruster, D. N. Yates, 1995. Non-aqueous-phase fluids in heterogeneous aquifers - Experimental study. Journal of environmental engineering. 121, 571-579.

Kamaruddin SA, Sulaiman WNA, Rahman NA, Zakaria MP, Mustaffar M, Sa'ari R., 2011. A review of laboratory and numerical simulations of hydrocarbons migration in subsurface environments. Journal of environmental science and technology. 4(3), 191-214. doi:10.3923/jest.2011.191.214.

Kechavarzi C., Soga K., Illangasekare T. H., 2005. Two-dimensional laboratory simulation of LNAPL infiltration and redistribution in the Vadose zone. Journal contaminant hydrology. 76(3-4):211-233.

Kim, T. J., and C. V. Chrysikopoulos, 1999. Mass transfer correlations for nonaqueous phase liquid pool dissolution in saturated porous media, Water resource research. 35(2), 449459.

Kumar, A., Datta, M., Nema, A. K., and Singh, R. K. 2016. An improved rating system for assessing surface water contamination potential from MSW landfills. Environmental Modeling and Assessment, 21(4), 489-505.

Lee, K. Y., and C. V. Chrysikopoulos, 1998. NAPL pool dissolution in stratified and anisotropic porous formations, J. Environmental engineering. 124(9), 851-862.

Legout C, Molenat J, Hamon Y., 2009. Experimental and modeling investigation of unsaturated solute transport with water-table fluctuation. Vadose zone journal. 8:21-31.

Lenhard R. J., Oostrom M, Dane J.H., 2004. A constitutive model for air- NAPL-water flow in the vadose zone accounting for immobile, non-occluded (residual) NAPL in strongly water-wet porous media. Journal contaminant hydrology. 71(1-4):261-282.

Mobile, M. A., Widdowson, M. A., and Gallagher, D. L. 2012. Multicomponent NAPL source dissolution: Evaluation of mass-transfer coefficients. Environmental science and technology. 46(18), 10047-10054.

Mustapha, H. I., Gupta, P. K., Yadav, B. K., van Bruggen, J. J. A., and Lens, P. N. L. 2018. Performance evaluation of duplex constructed wetlands for the treatment of diesel contaminated wastewater. Chemosphere, 205, 166-177. 
669

670

671

672

673

674

675

676

677

678

679

680

681

682

683

684

685

686

687

688

689

690

691

692

693

694

695

696

697

698

Nambi, I.M., and Powers, S.E., 2000. NAPL dissolution in heterogeneous systems: an experimental investigation in a simple heterogeneous system. Journal contaminant hydrology. 44, 161-184.

Nambi, I.M., and Powers, S.E., 2003. Mass transfer correlations for nonaqueous phase liquid dissolution from regions with high initial saturations. Water resource research. 39 (2).

Neale, C. N., Hughes, J. B., and Ward, C. H., 2000. Impacts of unsaturated zone properties on oxygen transport and aquifer reaeration. Groundwater. 38(5), 784-794.

Nema, A. K., and Gupta, S. K. 1999. Optimization of regional hazardous waste management systems: an improved formulation. Waste Management, 19(7-8), 441-451.

Nema, A. K., and Gupta, S. K. 2003. Multiobjective risk analysis and optimization of regional hazardous waste management system. Practice Periodical of Hazardous, Toxic, and Radioactive Waste Management, 7(2), 69-77.

Oostrom, M., Dane, J. H., and Wietsma, T. W., 2007. A review of multidimensional, multifluid, intermediate-scale experiments: Flow behavior, saturation imaging, and tracer detection and quantification. Vadose zone journal. 6(3), 610-637.

Oostrom, M., Hofstee, C., and Wietsma, T. W. 2006. LNAPLs do not always float: an example case of a viscous LNAPL under variable water table conditions (No. PNNL-SA-48870). Pacific Northwest National Laboratory (PNNL), Richland, WA (US), Environmental Molecular Sciences Laboratory (EMSL).

Patterson B. M. and Davis G. B., 2009. Quantification of vapor intrusion pathways into a slabon-ground building under varying environ- mental conditions. Environ Science and Technology. 43(3):650-656.

Picone, S., Grotenhuis, T., van Gaans, P., Valstar, J., Langenhoff, A., and Rijnaarts, H., 2013. Toluene biodegradation rates in unsaturated soil systems versus liquid batches and their relevance to field conditions. Applied microbiology and biotechnology. 97(17), 78877898.

Power S.E. and Heermann S.E., 1999. Potential ground and surface water impacts, appendix B: Modeling interface mass-transfer processes" presented in "A critical review: the effect of ethanol in gasoline on the fate and transport of BTEX in the subsurface", Editors Cannon G. and Rice D., UCRL-AR-135949 Vol.4, chapter 2. 
699

700

701

702

703

704

705

706

707

708

709

710

711

712

713

714

715

716

717

718

719

720

721

722

723

724

725

726

727

728

729

Powers, S.E., Abriola, L.M., Dunkin, J.S., Weber, W.J., 1994a. Phenomenological model for transient NAPL-water mass transfer processes. Journal contaminant hydrology. 16, 133.

Powers, S.E., Abriola, L.M., Weber Jr., W.J., 1992a. An experimental investigation of nonaqueous phase liquid dissolution in saturated subsurface systems: steady state mass transfer rates. Water resource research. 28 (10), 2691 - 2705.

Powers, S.E., Abriola, L.M., Weber, W., 1994b. An experimental investigation of NAPL dissolution in saturated subsurface systems: transient mass transfer rates. Water resource research. 30, 321-332.

Powers, S.E., Abriola, L.M., Weber, W.J., 1992b. An experimental investigation of nonaqueous phase liquid dissolution in saturated subsurface systems: steady state mass transfer rates. Water resource research. 28 (10), 2691-2705.

Rivett, M.O., Wealthall, G.P., Dearden, R.A., McAlary, T.A., 2011. Review of unsaturatedzone transport and attenuation of volatile organic compound (VOC) plumes leached from shallow source zones. Journal of contaminant hydrology 123, 130-156.

Rolle, M., Eberhardt, C., Chiogna, G., Cirpka, O. A., and Grathwohl, P., 2009. Enhancement of dilution and transverse reactive mixing in porous media: Experiments and modelbased interpretation. Journal of contaminant hydrology, 110(3-4), 130-142.

Saba, T.A., Illangasekare, T.H., 2000. Effect of ground-water flow dimensionality on mass transfer from entrapped nonaqueous phase liquid contaminants. Water resource research. $36(4), 971-979$.

Sarikurt, D. A., Gokdemir, C., and Copty, N. K., 2017. Sherwood correlation for dissolution of pooled NAPL in porous media. Journal of contaminant hydrology. 206, 67-74.

Simunek, J., T. Vogel, and M.Th. van Genuchten., 1996. HYDRUS-2D code for simulating water flow and solute transport in two-dimensional variably saturated media. Version 1.0. USDA/ARS, U.S. Salinity Lab., Riverside, CA.

Šimunek, J., Van Genuchten, M. T., and Šejna, M. (2012). HYDRUS: Model use, calibration, and validation. Transactions of the ASABE, 55(4), 1263-1274.

Sulaymon, A., and H.A. Gzar., 2011. Experimental investigation and numerical modelling of light non-aqueous phase liquid dissolution and transport in a saturated zone of the soil. Journal of Hazardous Materials. (186), 1601-1614. 
Vasudevan, M., G. Suresh Kumar, N. Indumathi M., 2014. Numerical study on kinetic/equilibrium behaviour of dissolution of toluene under variable subsurface conditions. European journal of environmental and civil Engineering. 18(9), pp.10701093.

Yadav B.K., and Hassanizadeh S.M., 2011. An overview of biodegradation of LNAPLs in coastal (semi)-arid environment. Water air soil pollution. 220, 225-239.

Yadav B.K., Ansari FA, Basu S, Mathur A., 2013. Remediation of LNAPL contaminated groundwater using plant-assisted biostimulation and bioaugmentation Methods". Water air soil pollution. 225, 1793 .

Yadav, B.K., Shrestha, S.R. and Hassanizadeh, S.M., 2012. Biodegradation of toluene under seasonal and diurnal fluctuations of soil-water temperature. Water, air, and soil pollution, 223(7), pp.3579-3588.

Zhang Q, Wang G.C., Sugiura N, Utsumi M, Zhang ZY, Yang YN., 2014. Distribution of petroleum hydrocarbons in soils and the underlying unsaturated subsurface at an abandoned petrochemical site, North China. Hydrological process. 28, 2185-2191.

745 Zhou, A. X., Zhang, Y. L., Dong, T. Z., Lin, X. Y., and Su, X. S., 2015. Response of the microbial community to seasonal groundwater level fluctuations in petroleum hydrocarbon-contaminated groundwater. Environmental science and pollution research. 22(13), 10094-10106. 